Produto \& Produção, vol. 16 n.2, p. 56-80, jun. 2015

RECEBIDO EM 28/06/2014. ACEITO EM 15/06/2015.

\title{
Uma abordagem para construção de modelos de simulação a eventos discretos para aplicação como um recurso didático
}

\author{
Cíntia de Lima Rangel \\ Instituto Federal Fluminense - IFF Campos \\ cintiade.lima@yahoo.com.br \\ Joao Jose de Assis Rangel \\ Universidade Candido Mendes - UCAM Campos \\ joao@ucam-campos.br \\ Janaina Ribeiro do Nascimento \\ Instituto Federal Fluminense - IFF Campos \\ jrnasciemento@iff.edu.br
}

\section{RESUMO}

O objetivo do presente trabalho é apresentar uma proposta de abordagem para auxiliar o desenvolvimento de modelos de simulação a eventos discretos empregados como recurso de apoio didático. Apesar de existirem várias abordagens metodológicas para auxiliar a construção de modelos de simulação, nenhuma delas apresenta, de forma direta, os elementos necessários para a construção de um modelo de simulação empregado com fins didáticos. Assim, três metodologias abordadas com larga aplicação e citações na área foram avaliadas. Verificaram-se, também, os elementos essenciais necessários para a elaboração de um modelo de simulação para ser construído por um professor não especialista em simulação discreta. Dois modelos de simulação foram elaborados por dois professores das disciplinas de Informática e Física como forma de testar a abordagem proposta. A versão Student do software Arena v. 14.0, que é livre de custos, foi utilizada em ambos os modelos como ambiente de desenvolvimento dos modelos de simulação. Os modelos foram aplicados em aulas das respectivas disciplinas e se mostraram adequados para auxiliar a explanação e a visualização dos conceitos dinâmicos exigidos para a apresentação dos conteúdos abordados.

Palavras-chave: Simulação a eventos discretos, simuladores, recursos didáticos.

\begin{abstract}
The aim of this paper is to present an approach proposal to assist the development of discrete event simulation models used as a didactic support resource. Despite existing various methodological approaches to help the construction of simulation models, none of them present, directly, the necessary elements for the construction of a simulation model with didactic purpose. Thus, three methodologies addressed with wide application and citations in the area were evaluated. The essential elements needed for the elaboration of a simulation model to be constructed by a teacher which is not a specialist in discrete simulation were verified. Two simulation models were elaborated by two teachers
\end{abstract}


of the disciplines of Physics and Informatics as a way to test the proposal approach. The student version of Arena software v. 14.0, which is free of costs, was used in both models as a development environment of the simulation models. The models were applied in classes of the respective disciplines and were considered appropriated to help explanation and visualization of the dynamic concepts required for the presentation of the contents approached.

Key-words: Discrete event simulation, simulators, didactic resources.

\section{Introdução}

Segundo White e Ingalls (2009), existem duas categorias de aplicação para a simulação computacional. A primeira relaciona-se com a formação e treinamento de pessoas. Ou seja, profissionais das mais variadas áreas podem utilizar os ambientes simulados para, por exemplo, aperfeiçoarem suas habilidades práticas ou, até mesmo, aprenderem certos procedimentos que envolvam alto risco. A segunda categoria inclui aplicações em análise e/ou em projetos de dispositivos ou processos, sendo amplamente utilizada por empresas para auxiliar, principalmente, a tomada de decisão, o trabalho de Miranda et al. (2012) descreve um caso típico desta aplicação.

Em relação à primeira categoria, Goldsman (2007) foi um dos pioneiros a chamar a atenção para o fato de que a simulação computacional poderia ser empregada, também, de forma simples, como um recurso didático em aulas do ensino médio, em disciplinas como Matemática, por exemplo. Neste trabalho, foi demonstrado, especificamente, como a simulação a eventos discretos (SED) poderia auxiliar professores, através do uso de pequenos modelos de simulação em aulas, a ajudarem os alunos a compreenderem melhor certos conteúdos da disciplina. Note que a proposta do autor extrapolou as aplicações típicas da área. Ou seja, normalmente, quando a simulação computacional é empregada no ensino e treinamento, são utilizados simuladores específicos para uma determinada aplicação. Muitas vezes, estes simuladores exigem hardwares específicos também e são construídos com linguagens como $\mathrm{C}$ ou Java, que exigem programadores experientes. Por outro lado, quando se utiliza a SED para a construção de modelos empregados na análise de um sistema e auxílio na tomada de decisão, são utilizadas linguagens e/ou ambientes como Arena, ProModel ou Simul8, citando apenas os mais usados no Brasil. Desta forma, o que o autor propôs foi a união de dois mundos que estavam próximos mas não se tocavam. O primeiro: modelos para ensino, construídos pelos próprios professores, utilizando computadores pessoais comuns; e o segundo: emprego dos ambientes de SED (Arena, ProModel, Simul8 ou outros) para o desenvolvimento destes modelos.

Atualmente, existem seções específicas de simulação empregada em educação nos principais eventos internacionais sobre o assunto. As aplicações são encontradas nas mais diversas áreas de ensino. Trabalhos como Montevechi et al. (2013), Balci, Deater-Deckard e Norton (2013), Ståhl, Born e Herper (2013), e Rangel et al. (2010) dão a dimensão da amplitude que se pode chegar neste campo. Especificamente, o trabalho de Silva et al. (2014) demonstrou a aplicação de modelos de SED em aulas de curso técnico de nível médio para treinamento de conceitos de comunicação digital na área de Telecomunicações. Na realidade, o que foi proposto, de forma comum, por estes trabalhos citados, foi a construção de modelos de simulação de maneira simples e prática por um professor, da mesma forma que ele poderia elaborar uma planilha ou uma apresentação para enriquecer a explicação de suas aulas. Ou seja, no momento em que um professor perceber a necessidade de ter um instrumento que possa auxiliá-lo na explanação e visualização dinâmica de um determinado conteúdo de uma aula, ele poderá utilizar um modelo de simulação para auxiliá-lo neste propósito. A partir desta perspectiva, o que se vê é uma ampliação do campo da SED quando o assunto é ensino e treinamento. Isto pode ser justificado, já que esses modelos são preparados por pessoas não especialistas em simulação e os mesmos não são empregados com propósito de análise de algum sistema tipicamente abordado na área da SED.

Normalmente, modelos de simulação são elaborados por especialistas da área após, no mínimo, meses de experiência. O que está sendo proposto agora é que modelos de simulação sejam elaborados por professores de variadas disciplinas, principalmente do ensino médio, não especialistas em modelagem e simulação. Esta proposta se fundamenta a partir da facilidade de programação, também podendo se dizer de "manuseio", dos softwares atuais utilizados na construção dos modelos de simulação discreta. A palavra manuseio pode ser utilizada uma vez que o professor pode elaborar um modelo de forma simples, sem ser um especialista em programação de computadores. 
Como destacado por Law (2007) e Banks (2010), os ambientes de SED oferecem uma gama de recursos para o desenvolvimento de modelos de simulação, tais como gráficos, mostradores, contadores, entre outros, além de permitir a animação gráfica. Hoje, esses ambientes são softwares de grande capacidade a ponto de permitir a construção de modelos de simulação em tempo curto e com alto grau de detalhes. Nestes ambientes, não é necessário escrever muitas linhas de código, pois o processo de criação do modelo de simulação é gráfico, visual e de maneira integrada, utilizando blocos gráficos, que representam várias funções. Ou seja, do ponto de vista da programação, é relativamente simples construir um modelo de SED. No entanto, pode-se obter uma solução de grande capacidade e complexidade em pouco tempo e a baixo custo.

Diante da perspectiva exposta, o objetivo deste trabalho é propor uma abordagem para construção de modelos de SED para serem utilizados como recurso didático, usando softwares livres de custos. Segundo Sargent (2013), a abordagem metodológica utilizada na simulação pode ser vista como uma ferramenta composta por passos ou procedimentos que conduzam à representação adequada de um sistema através de modelos de simulação. A construção do modelo de simulação é um processo que requer um planejamento de etapas. Este planejamento é necessário para que se definam claramente os objetivos do modelo idealizado e também que se minimize a ocorrência de erros.

$\mathrm{O}$ artigo está organizado da seguinte forma. Após este item introdutório, apresenta-se a descrição das metodologias de simulação na seção 2. A seção 3 apresenta, então, uma proposta de abordagem para construção de modelos didáticos. Na seção 4 são apresentados os testes e avaliações propostos pela nova abordagem, sendo realizados, diretamente em dois modelos didáticos construídos de acordo com os passos propostos pela nova abordagem e construção. A seção 5 finaliza o artigo com suas considerações finais a respeito dessa nova proposta de abordagem de construção de modelos didáticos, além de apresentar sugestões de trabalhos futuros.

\section{Metodologia de simulação}

Existem várias metodologias empregadas na construção de modelos de simulação a eventos discretos propostas pela bibliografia especializada na área. Porém, como já era esperado, nenhuma delas apresenta, de forma direta, os elementos necessários para a construção de um modelo de simulação com fins didáticos.

Antes de propor uma abordagem para construção de modelos didáticos, foi feito inicialmente uma descrição das três metodologias com larga aplicação e citações na área. Esse procedimento facilitou a escolha dos elementos essenciais à elaboração de um modelo de simulação didático a ser construído por um professor não especialista em simulação discreta. A seleção dessas três metodologias teve como critério a escolha de duas metodologias descritas na literatura internacional e uma na nacional. Neste contexto, considerou-se como base o ano de publicação da primeira edição dos livros, assim como o lançamento de novas edições. A escolha recaiu sobre as metodologias apresentadas em Banks et al. (2010), Law (2007) e Freitas Filho (2008), respectivamente.

Inicialmente, foi realizada uma comparação entre estas três metodologias, de modo a verificar os pontos comuns e particulares entre os passos sugeridos pelos autores. A Figura 1 traz o número e a sequência dos passos propostos nas três metodologias analisadas.

Observando a Figura 1, é possível notar que o número de passos sugeridos pelos autores, assim como sua sequência, podem apresentar semelhanças e diferenças. Na metodologia de Banks et al. (2010), foram observadas doze fases. Já, na metodologia de Law (2007), foram detectadas dez etapas. Por fim, na metodologia proposta por Freitas Filho (2008), foram detectadas doze etapas para elaboração de um modelo de simulação, assim como na metodologia de Banks et al. (2010).

$\mathrm{Na}$ análise do primeiro passo, observou-se que os três autores sugeriram as mesmas funções para serem executadas.

No segundo passo, nota-se que houve uma diferença em relação às funções executadas por Law (2007), pois o autor sugere que aqui sejam realizadas tarefas distribuídas nos passos dois, três e quatro, indicados na metodologia proposta por Banks et al. (2010). Nesta etapa, Law (2007) sugere que se faça a coleta de informações sobre o leiaute e o nível de detalhamento do sistema a fim de facilitar a construção do modelo conceitual, e que se realize uma coleta de dados para fins de validação. Além disto, o autor ainda propõe que se comece com um modelo simples que facilite a execução e evite possíveis erros. Na visão de Banks et al. (2010), nesta fase, deve-se somente definir 
que questões a simulação deverá responder, quais os custos envolvidos no processo e qual o tempo necessário para executar este trabalho. Na visão de Freitas Filho (2008), este passo deve ser composto pela realização de um levantamento sobre os recursos e custos necessários à modelagem e simulação. Além disto, também deverá ser feito um cronograma das atividades desenvolvidas.

No terceiro passo, Banks et al. (2010) e Freitas Filho (2008) compartilham da mesma ideia quando indicam a construção do modelo conceitual para traduzir a lógica obtida pelo levantamento das informações sobre o sistema. Já, Law (2007) propõe que neste momento seja feita a validação dos dados levantados no passo anterior.

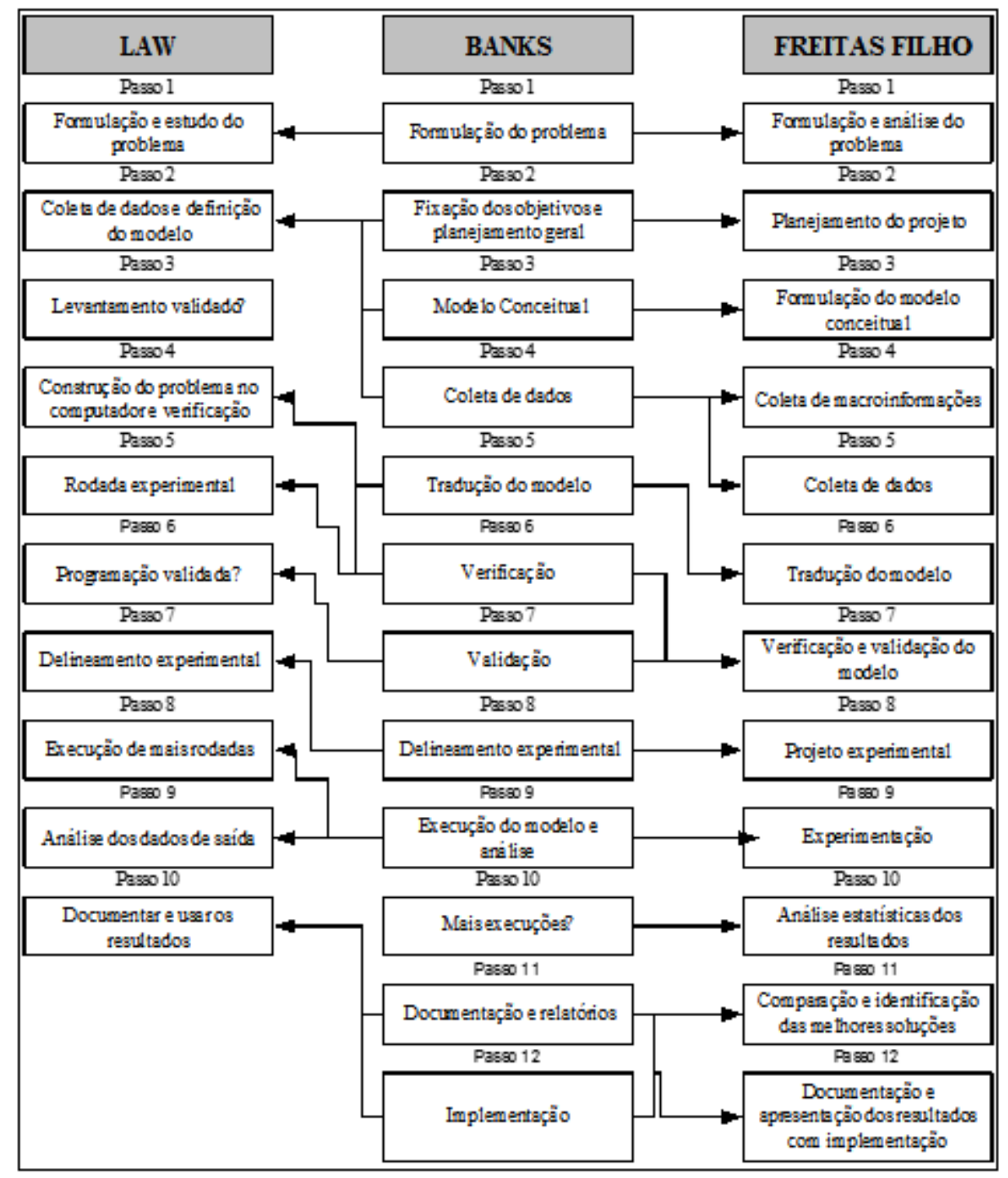

Figura 1- Comparação entre as diferentes metodologias de simulação

No quarto passo, Banks et al. (2010) sugerem a coleta do conjunto de dados que fará parte do modelo, para que o mesmo seja posteriormente validado. $\mathrm{O}$ autor recomenda, ainda, que esta fase se inicie o mais cedo possível, pois leva um tempo considerável em relação às outras tarefas que fazem parte da construção de um modelo de simulação. Esta mesma tarefa é dividida em dois passos, de acordo com Freitas Filho (2008): a coleta de macro informações no passo quatro e a coleta de dados no passo cinco, onde são levantadas informações importantes sobre a alimentação do sistema modelado como a fonte de dados será usada. A estrutura ou dinâmica do sistema, a adequação do formato dos dados em relação ao modelo e os custos envolvidos neste processo. Na proposta de Law (2007), deve-se traduzir o problema para o computador utilizando uma linguagem de programação ou um software de simulação e, em seguida, fazer a verificação do modelo simulado. Neste caso, percebese que este passo foi composto dos passos cinco e seis de Banks et al.(2010). 
No quinto passo, propõe-se a tradução do modelo conceitual para a forma computacional, gerando assim um modelo operacional (BANKS et al., 2010). Para Law (2007), esta tarefa já foi realizada no passo quatro. Ainda de acordo com o autor, a função a ser executada neste passo é a realização de testes ou experimentos com o objetivo de validar o modelo na etapa seis. Já para Freitas Filho (2008), a tarefa do quinto passo é a coleta de dados já mencionada no parágrafo anterior.

No sexto passo, deverá ser verificado se a lógica do sistema está bem representada pelo modelo computacional e se o modelo está funcionando conforme a expectativa do programador (BANKS et al., 2010). De acordo com Freitas Filho (2008), neste passo, deve-se construir o modelo computacional a partir do modelo conceitual e dos dados coletados sobre o sistema. Na visão de Law (2007), nesta etapa, deve-se questionar se o modelo computacional está validado, analisando os resultados obtidos no modelo e comparando, sempre que possível, com outros resultados sobre o sistema simulado.

No sétimo passo, Banks et al. (2010) propõem a validação a fim de comparar as respostas do modelo simulado com o real, e utilizar as discrepâncias encontradas e o conhecimento adquirido para aperfeiçoar o modelo. Para Law (2007), esta etapa, que é chamada de delineamento experimental ou projeto experimental, deve ser composta pela definição do número de replicações e tempo de execução necessários ao modelo, além de números aleatórios e diferentes para cada rodada. Já, para Freitas Filho (2008), este passo é composto pelo passo seis e sete proposto por Banks et al. (2010), ou seja, verificação e validação. Freitas Filho (2008) sugere aqui que se avalie o comportamento do modelo. Se ele opera em conformidade com a proposta do analista, se a lógica está bem representada e se os resultados obtidos são coerentes com os resultados do modelo real.

No oitavo passo, tanto Freitas Filho (2008) quanto Banks et al. (2010) sugerem que seja definido como cada um dos testes no modelo deve ser realizado, considerando parâmetros como tempo de duração da simulação e número de replicações. Para Law (2007), esta etapa serve para executar mais rodadas para facilitar a análise no próximo passo.

No nono passo, Banks et al. (2010) sugerem a execução de várias rodadas da simulação para posterior análise. Essa proposta também é sugerida por Freitas Filho (2008) quando o mesmo indica que, nesta etapa, devem-se executar as simulações e analisar os seus resultados para que os mesmos sirvam de parâmetro para simulações futuras. Do ponto de vista de Law (2007), o nono passo determina que os dados de saídas devem ser analisados, comparando o desempenho de determinadas configurações do sistema com sistemas alternativos.

No décimo passo, Law (2007) finaliza sua metodologia de construção de um modelo de simulação, pois utiliza os passos onze e doze da proposta de Banks et al. (2010) com a documentação e utilização dos resultados em projetos atuais e futuros. Para Banks et al., a décima etapa deve questionar a necessidade de rodadas ou testes adicionais. Já, Freitas Filho (2008) sugere uma análise estatística dos resultados, de modo que se interpretem os dados, a fim de verificar a necessidade de mais replicações, pois o aumento do número de replicações pode alcançar melhores resultados.

No décimo primeiro passo, Banks et al. (2010) propõem levantar a documentação e relatórios sobre o modelo de simulação, tendo, na documentação, a finalidade de descrever os processos utilizados na programação para que outros analistas possam manipular o modelo ou construir outro similar. Além disto, a documentação também pode ser vista como um guia para orientar os usuários interessados no modelo a alterar seus parâmetros com o objetivo de otimizar os resultados na saída do modelo. Já, para Freitas Filho (2008), esta etapa, que é chamada de "comparação e identificação das melhores soluções", é uma fase onde se faz um confronto com outros resultados obtidos em sistemas alternativos ou equivalentes para que se identifique a melhor resposta ou a mais adequada.

Sobre o décimo segundo e último passo, Banks et al. (2010) afirmam que o sucesso da fase de implementação depende de uma boa execução dos passos anteriores, do envolvimento do analista durante a construção e testes no modelo e, como consequência, se o usuário compreende os resultados do modelo. Para Freitas Filho (2008), a última fase concentra a documentação e apresentação dos resultados e a implementação, onde, primeiramente, se faz a descrição de todas as características necessárias ao desenvolvimento do modelo, e, assim, os métodos utilizados na análise dos resultados e suas conclusões. Em seguida, é feita uma exposição de todo o resultado para o grupo que fez parte do desenvolvimento do modelo. Por fim, o projetista irá relatar a parte interessada na simulação do sistema para que a mesma possa tomar decisões baseada nos resultados apresentados.

Após a discussão das três metodologias já consolidadas, observa-se que em todas elas 
convergem para o mesmo resultado. Não havendo diferença de qualidade ou desempenho entre modelos que são construídos com base nos passos sugeridos por um dos três autores. $\mathrm{O}$ que se observa nessa análise é que alguns autores como Law (2007) condensam algumas etapas em um único passo com nome diferente. Já outros como Banks (2010), desmembram uma etapa em várias. A importância da análise das etapas indicadas por cada um dos três autores é fundamentar a proposta de desenvolvimento de uma abordagem específica para construção de modelos didáticos.

\section{Abordagem para construção de modelos didáticos}

A abordagem proposta neste trabalho para ser utilizada como referência na construção de modelos de simulação com fins didáticos sugere a realização de seis etapas ou "passos", apresentadas na Figura 2. Estas etapas são as seguintes: formulação e análise do conteúdo; análise de viabilidade e definição dos objetivos; modelo conceitual; modelo computacional com animação; testes com o modelo; documentação e implementação. Note que o número de passos propostos são bem menores que as abordagens clássicas de simulação discreta. Isto se deve ao fato de o modelo didático aqui proposto não ter a pretensão de tratar por simulação um problema típico de um sistema dinâmico determinístico ou estocástico. $\mathrm{O}$ foco da proposta é a animação que pode ser obtida para uso como recurso didático a partir da utilização de um software de simulação discreta por um professor não especialista em simulação. Ou seja, a mesma questão levantada por Goldsman (2007), apresentada na Introdução deste trabalho.

Ressalta-se que os passos sugeridos na abordagem proposta considera que o professor precisará receber um treinamento básico e introdutório de aproximadamente 20 horas sobre a utilização de um software de SED. No caso específico deste trabalho, a pesquisa foi conduzida com o software de simulação Arena. No entanto, dada a semelhança existente entre os softwares empregados para a construção de modelos de SED, não se espera que haja uma diferença significativa em relação ao tempo de treinamento exigido se outro software for utilizado.

$\mathrm{Na}$ etapa de formulação e análise do conteúdo, deve ser realizado um levantamento sobre a necessidade de abordar o conteúdo através de software de SED; outro levantamento sobre a natureza (discreta ou contínua) do modelo; e, no caso de ser um sistema contínuo, se é possível discretizá-lo em um modelo de SED.

$\mathrm{Na}$ análise de viabilidade e definição dos objetivos, é recomendado que se faça uma reflexão sobre a viabilidade do uso do modelo de SED em sala de aula. Para isto, são feitos os seguintes questionamentos: se o ambiente de sala de aula oferece recurso adequado para a execução do programa e visualização dos efeitos de animação e, caso o modelo seja interativo, se existe um ambiente (sala de aula ou laboratório de Informática) com um número suficiente de computadores que possa servir de interface entre o aluno e o modelo computacional. Após esta primeira análise, o próximo passo é definir os objetivos do modelo, ou seja, quais pontos do conteúdo a ser modelado o professor deseja representar. Isto é importante, pois existe conteúdo com uma abordagem muito extensa e complexa. Deste modo, se o programador insistir em representar todos os conceitos presentes em um conteúdo complexo, poderá resultar em erro. Neste contexto, o programador deve utilizar a simulação para representar os pontos considerados mais relevantes por ele. Sendo assim, o modelo irá se apresentar numa forma mais simplificada, podendo facilitar o entendimento do aluno.

A construção do modelo conceitual tem o objetivo de traduzir os conceitos do sistema que se pretende modelar, dando a ele uma estrutura que irá orientar e facilitar sua transição para a modelagem computacional. Isto ocorre porque o modelo conceitual evidencia o contexto do sistema, a integração das partes envolvidas e o formato lógico do modelo. Nesta etapa, é de extrema importância que se observe se existe erro entre a lógica dos conceitos e sua representação através do modelo conceitual. Essa verificação evitará ocorrência de erros durante a tradução para o modelo computacional.

$\mathrm{Na}$ construção do modelo computacional, o professor irá traduzir o conteúdo teórico modelado na forma conceitual para um software de SED. Após a construção do modelo computacional, será utilizado o recurso de animação para materializar os conceitos abstratos modelados no SED. Também pode ser utilizado o recurso de interatividade no modelo, proporcionando que o aluno interaja diretamente com o simulador. 
Os testes com o modelo são realizados com o propósito de verificar a qualidade e a eficácia do modelo. Inicialmente, analisa-se a capacidade do modelo em representar os conceitos e a lógica do conteúdo teórico proposto. Também é verificado se as etapas representadas no modelo conceitual estão coerentes com as programadas no modelo computacional. Além disto, é testada a qualidade visual da animação construída a partir do modelo. Esta primeira fase de testes pode contar com a colaboração de outros professores que ministram o conteúdo, e, até mesmo, levar em consideração a opinião do aluno. Desta forma, os testes visuais poderão resultar em modelos de melhor qualidade.

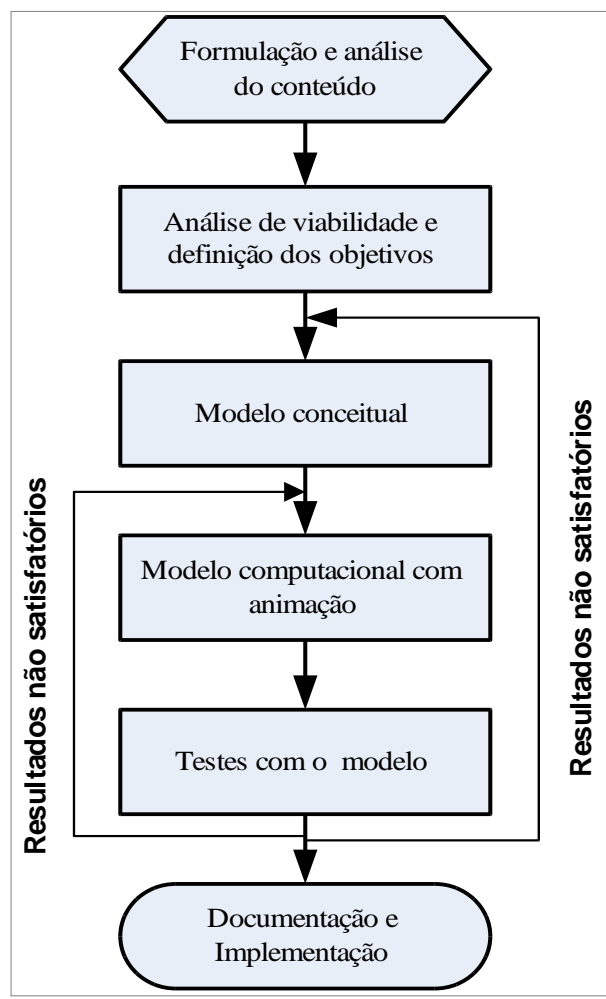

Figura 2 - Etapas da abordagem de simulação de modelos didáticos

No teste de eficácia do modelo, o professor poderá fazê-lo de duas formas: testando o modelo em um pequeno grupo de alunos, a fim de confirmar a contribuição do modelo de simulação didático no processo de aprendizagem, para depois implementá-lo em sala de aula ou realizando esse teste no dia a dia com os alunos. Assim, ele poderá verificar se a ferramenta construída por ele contribui ou não para a aprendizagem dos seus discentes.

Avaliar a eficiência do modelo se justifica pelo fato de que toda ferramenta de ensino usada em sala de aula tem o objetivo de elevar ou gerar novos conhecimentos aos alunos. Desta forma, a legitimidade de qualquer método, seja ele a própria fala do docente, um vídeo, uma imagem ilustrativa ou uma prática de laboratório, só será confirmada quando sua aplicação estimular a aprendizagem dos alunos. Desta forma, é sugerida, para melhor avaliação do modelo, a aplicação de um pré-teste antes da exposição do aluno ao simulador. Assim, o professor poderá comparar os resultados que antecedem e sucedem à aplicação do simulador. Isto porque, após o simulador, o mesmo teste poderá ser repetido, a fim de verificar o que o aluno aprendeu.

Se o resultado do teste for considerado insatisfatório, será recomendado o retorno à etapa de construção do modelo conceitual. Esse procedimento é indicado, pois o professor pode ter construído um modelo computacional com base em um modelo conceitual muito complexo, relação aos conceitos que ele desejava reproduzir através de um modelo didático.

Com relação à qualidade da animação, se durante a exposição do modelo for constatado a falta de qualidade nas imagens, ou na dinâmica apresentada, será necessário retornar a etapa de construção do modelo computacional. Esse procedimento será para realizar os ajustes necessários para uma melhor representação do conteúdo.

A etapa de documentação e implementação do modelo se inicia com um relatório composto 
pelo modelo conceitual e o passo a passo da tradução para a forma computacional, através do ambiente de SED. A documentação tem o objetivo de relatar detalhes do seu desenvolvimento, objetivando sua reprodução por outro programador ou uma futura modificação. Logo após, este modelo poderá ser implementado em sala de aula pelo professor que o construiu, ou por outros professores que ministram os conteúdos simulados no modelo. A implementação é o que dá sentido à metodologia apresentada neste trabalho, pois se caracteriza pela aplicação do modelo em sala de aula como recurso didático reconhecido pela etapa de testes.

\section{Testes e avaliação da abordagem proposta}

Este item apresenta dois modelos de simulação construídos para serem utilizados como recursos didáticos. O primeiro refere-se a um modelo de simulação para auxiliar em uma explanação dinâmica de uma aula em curso técnico de nível médio em disciplina de Informática. $\mathrm{O}$ assunto abordado diz respeito ao tópico sobre Camadas OSI (Open Systems Interconnection) ou, em português, Interconexão de Sistemas Abertos, que é uma forma padrão de interligação de computadores. O segundo modelo aborda conceitos de óptica geométrica, como a Lei da Refração ou Lei de Snell. Este também é um assunto comumente ensinado em aulas de ensino médio no escopo de uma disciplina de Física.

Dos dois modelos de simulação aqui apresentados, o primeiro foi elaborado seguindo as etapas propostas neste trabalho. Já, no segundo modelo, uma vez que foi criado antes da nova proposta de metodologia de construção de um modelo de simulação didático, foram identificados os passos utilizados pelo professor em cada uma das etapas propostas pela abordagem de construção de modelos com fins didáticos.

Vale ressaltar que os modelos foram construídos pelos respectivos professores de cada uma das disciplinas citadas, Informática e Física, no caso. Assim, pôde ser exposta a proposta em dois assuntos típicos de ensino médio, sendo eles de natureza distinta, ou seja, o modelo OSI discreto e o outro contínuo.

Para o desenvolvimento de ambos os modelos, utilizou-se a versão Student do software Arena v. 14.0 do software Arena. Esta versão pode ser obtida através na página da Internet da empresa Paragon, que comercializa o software no Brasil e na América do Sul (http://www.paragon.com.br/livropaulofreitas).

\subsection{Modelo para aula de informática no ensino médio: modelo OSI}

A arquitetura chamada OSI é um modelo de referência que divide as etapas envolvidas na comunicação entre redes, em sete camadas. Cada camada define uma funcionalidade que é implementada por protocolos e equipamentos de redes. Este é um tópico normalmente ensinado em cursos introdutórios de redes de computadores e, normalmente, não há muitos recursos disponíveis que possam auxiliar a explanação de um professor.

\subsubsection{Formulação e análise do conteúdo}

Na formulação e análise do conteúdo, foi observada a amplitude e o grau de dificuldade dos conceitos relacionados ao conteúdo a ser modelado. Além disto, também foi considerada sua característica abstrata, o que dificulta, muitas das vezes, sua ilustração durante a aula.

O conteúdo a ser modelado foi caracterizado como contínuo, porém possível de ser discretizado a partir de um ambiente de SED. Também vale ressaltar que, até o presente momento, não foi encontrado nenhum simulador que represente as mudanças na informação associada às funções de cada camada do modelo OSI.

\subsubsection{Análise de viabilidade e definição dos objetivos}

$\mathrm{Na}$ análise de viabilidade e definição dos objetivos, foi constatado que a instituição de ensino na qual o professor deseja implementar o modelo como recurso didático possui infraestrutura 
adequada. Isto quer dizer que há computadores, televisores e projetores multimídia para exibição do modelo. Além disso, na definição dos objetivos, foi escolhido representar as principais funções executadas pelas sete camadas do modelo OSI assim como a mudança que a informação vai adquirindo ao passar por essas camadas, associadas ao encapsulamento e ao desencapsulamento. Desta forma, o modelo a ser construído poderá proporcionar ao aluno a visualização das funções das sete camadas deste modelo associadas a alguns protocolos que atuam em cada uma delas.

\subsubsection{Construção do modelo conceitual}

Para a construção do modelo conceitual, pode ser utilizada a linguagem IDEF-SIM proposta por Montevechi et al. (2010). Foram construídos dois modelos, onde o primeiro representa a parte geradora de sinal ou bits e o segundo, as etapas e funções do Modelo OSI.

O primeiro modelo, ou seja, a parte responsável por receber os bits gerados por uma planilha Excel e enviá-los ao sistema pode ser visto na Figura 3:

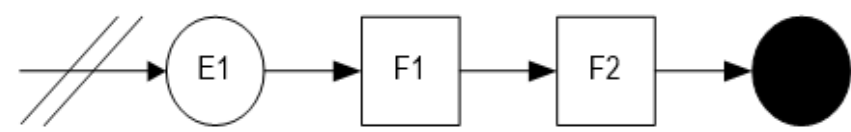

Figura 3 - Modelo conceitual da geração de bits para alimentação do modelo

O modelo conceitual do processo de geração de bits é a parte inicial que alimenta o modelo didático. Ele é responsável por receber os bits do Excel, onde o professor e/ou alunos poderão digitar a quantidade de bits de entrada do modelo. A descrição dos itens presentes nesta parte inicial do modelo conceitual pode ser vista no Quadro 1:

Quadro 1 - Descrição dos itens presentes no modelo conceitual do processo de geração de bits

\begin{tabular}{|c|c|c|}
\hline Item & Descrição & Parâmetros \\
\hline E1 & Gerador de sinal - bits de entrada & Constante; 1 por vez; Máximo: 1 \\
\hline F1 & Criação de variável & Nome: variável b \\
\hline F2 & Recebe variável do Excel & Recebe variável b \\
\hline
\end{tabular}

Observando o Quadro 1, verifica-se a presença de uma entidade chamada "Bits de entrada". Para receber os bits gerados no Excel, foram realizadas as funções F1 e F2, onde o F1 cria a variável b, que representa os bits do Excel, e o F2 recebe esta variável para inseri-la no sistema. Por fim, este processo de geração de bits é encerrado pelo finalizador de geração de bits.

A segunda parte do modelo conceitual, que define conceitos e funções de cada camada do Modelo OSI assim como a tabela que trazem as dos itens do modelo, pode ser visto nos Apêndices A e $\mathrm{B}$, respectivamente.

De acordo com o Apêndice A, a entrada do sistema mostra a entidade informação (E1), que na camada 1 será amplificada pelo processo $(\mathrm{F} 1)$ e terá seu formato binário definido pelo processo (F2).

Os bits da camada 1 transportados pelo (M1) até a camada 2 que irá formar quadros a partir do processo (F3), inserir neste quadro os endereços MAC de origem e destino usando o processo (F4) e adicionando técnicas de controle de erro no processo (F5).Com o quadro da camada 2 completo, o processo de inspeção de erro será executado pelo (F6). Conforme o resultado desta inspeção, o quadro será descartado (F8) e quadros corretos seguirão sua trajetória, obedecendo à fila (F7) para o acesso ao meio até a próxima camada.

Os quadros da camada 2 serão transportados pelo (M2) até a camada 3, onde passarão pelo processo de empacotamento (F9), definição de endereço IP (F10) e roteamento (F11) baseado no tipo de serviço. Após a definição do serviço, será encaminhada para o serviço orientado a conexão (F12), a saída do pacote para circuito virtual (E2) e para o serviço não orientado a conexão (F13), a saída do datagrama (E3).

A camada 4 irá receber do M3 as entidades E2 e E3, que passarão pelo decisor de transporte 
de protocolo de datagrama do usuário - User Datagram Protocol (UDP) ou protocolo de controle da transmissão - Transmission Control Protocol (TCP) (F14), encaminhando os datagramas (E3) para o transporte UDP (F15), passando os pacotes (E2) pelos processos do protocolo TCP como o controle de fluxo (F16), controle de sequência e erro (F17), e descartando pacotes com erro através do (F18).

A camada 5 recebe os dados pelo M4 e, através do controle de sessão F19, decidirá se a comunicação entre dois dispositivos será half (F20) ou full duplex (F21), de acordo com o fluxo da rede (preferência full duplex).

A camada 6 recebe os dados da camada 5 por meio do M5 e irá traduzir o conjunto de dados para seu formato original (F22) utilizando-se do código de compressão de imagens paradas - Joint Photographic Experts Group (JPEG) (F25), do código de compressão de imagens em movimento Moving Picture Experts Group (MPEG) (F24) ou através do Código Padrão Americano para o Intercâmbio de Informação - American Standard Code for Information Interchange (ASCII) (F23), para o caso de representação de textos.

A camada 7 pegará a informação do M6 representada pela camada 6 e a entregará ao destino através do servidor adequado utilizando um identificador de serviço do usuário (F26), que poderá ser o servidor de protocolo de transferência de Hipertexto - Hypertext Transfer Protocol (HTTP) (F27) para comunicação com a web, servidor de protocolo de transferência de arquivo - File Transfer Protocol (FTP) (F28) ou um servidor de domínio de nomes - Domain Name System (DNS) (F29).

\subsubsection{Construção do modelo computacional}

O computador utilizado no desenvolvimento do modelo computacional foi um notebook com as seguintes características: Windows 7, processador Intel Core i5, 2,4GHz, display de LED com 14 polegadas e resolução de 1366 x 768 pixels, memória RAM de 4096 MB DDR3 e HD 500 GB. Não foi preciso utilizar nenhum recurso adicional no desenvolvimento do modelo. O Quadro 2 descreve as características principais do modelo computacional apresentado neste trabalho.

Quadro 2 - Características do modelo de simulação

\begin{tabular}{|l|l|}
\hline Características & Software de simulação a eventos discretos \\
\hline Software de simulação & ARENA 14 \\
\hline Desenvolvedor & Professor da disciplina \\
\hline Tipo de licença & Gratuita \\
\hline Interatividade & Permite \\
\hline Alteração & Permite \\
\hline Grau de dificuldade de programação & Baixo \\
\hline Tempo de desenvolvimento & 15 horas \\
\hline Carga horária de treinamento & 20 horas \\
\hline
\end{tabular}

O Quadro 2 mostra que o modelo de simulação foi desenvolvido pelo próprio professor da disciplina, utilizando a versão livre do Arena. O modelo construído em Arena também permite sua alteração a qualquer tempo. $\mathrm{O}$ grau de dificuldade para sua construção foi considerado baixo, pois o docente que realizou a programação teve um treinamento de 20 horas e, mesmo assim, foi capaz de desenvolver um modelo didático e interativo com 15 horas de programação.

A parte inicial do modelo de simulação a eventos discretos, ou seja, a parte geradora de bits, utilizou os módulos Create, Assign, Read Write e Dispose. Já, os módulos utilizados na segunda parte do modelo, onde são representados os conceitos e funções de cada camada do Modelo OSI, foram: Create, Assign, Station, Router, Process, Decide e Dispose.

Os detalhes da organização e programação dos módulos do software Arena podem ser vistos em Rangel e Rangel (2013). Após a criação do modelo de SED, foi construída sua parte interativa, onde os alunos e professores podem inserir a quantidade de bits de entrada do modelo. A Figura 4 apresenta a tela de inserção dos bits para entrada do modelo: 


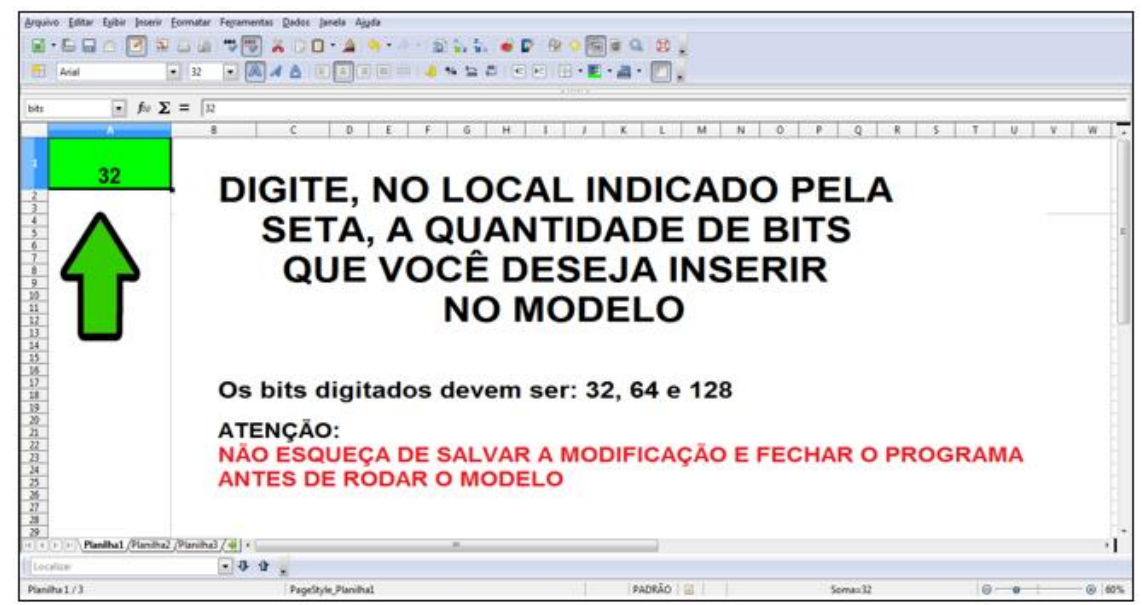

Figura 4 - Tela do Excel para inserção de dados

No que se refere à visualização do efeito que a alteração dos bits provoca no modelo, foi criada a tela de resultado no Arena. Esta tela mostra o valor correspondente a quantidades de bits do modelo e o tempo necessário que os bits levam para sair do sistema. A Figura 5 apresenta a tela do Arena com um painel de tempo e outro de quantidades de bits, antes da rodada do modelo.

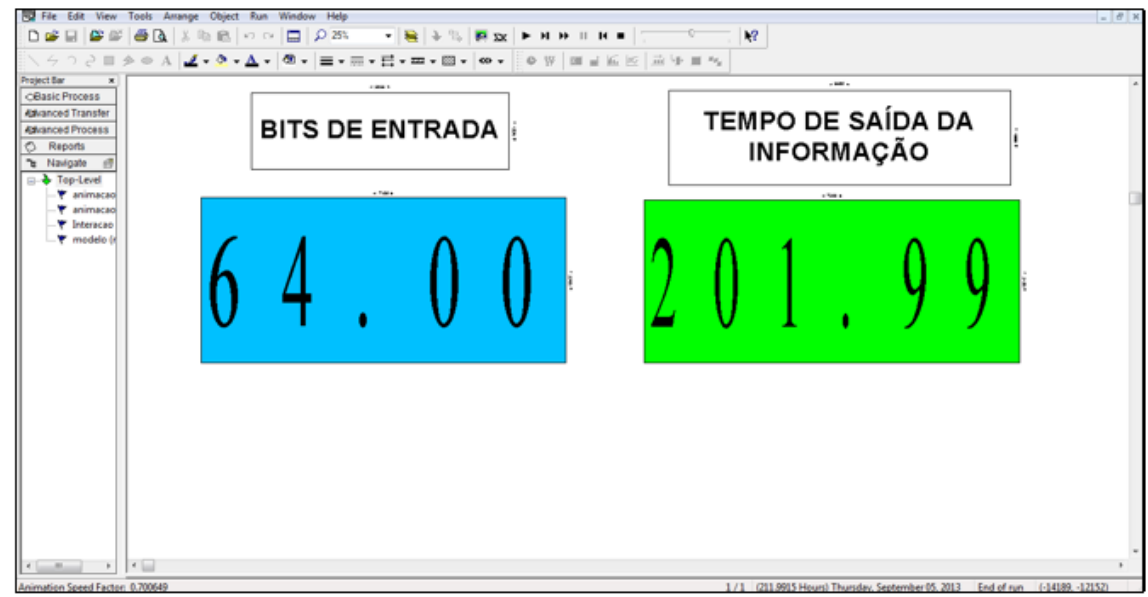

Figura 5 - Tela do Arena para visualização do tempo de saída de acordo com bits de entrada

O objetivo da tela, mostrada na Figura 5, é expor aos alunos a quantidade de bits que eles escolheram e o tempo que esta quantidade de bits leva para sair do modelo, considerando todas as camadas que irão percorrer.

Após a conclusão do modelo, foi utilizada a ferramenta de animação disponibilizada pelo software Arena. É através do recurso de animação que os alunos poderão visualizar os conceitos e funções simuladas no modelo de simulação a eventos discretos criado pelo professor. Para melhor compreensão e visualização das figuras, a animação foi dividida em duas partes, onde a parte "a" mostra a simulação das quatro primeiras camadas e a parte "b", a simulação das três últimas camadas.

Na parte "a" da animação, são representados os equipamentos e funções das camadas Física, Enlace, Rede e Transporte como mostram as Figura 6 e 7: 


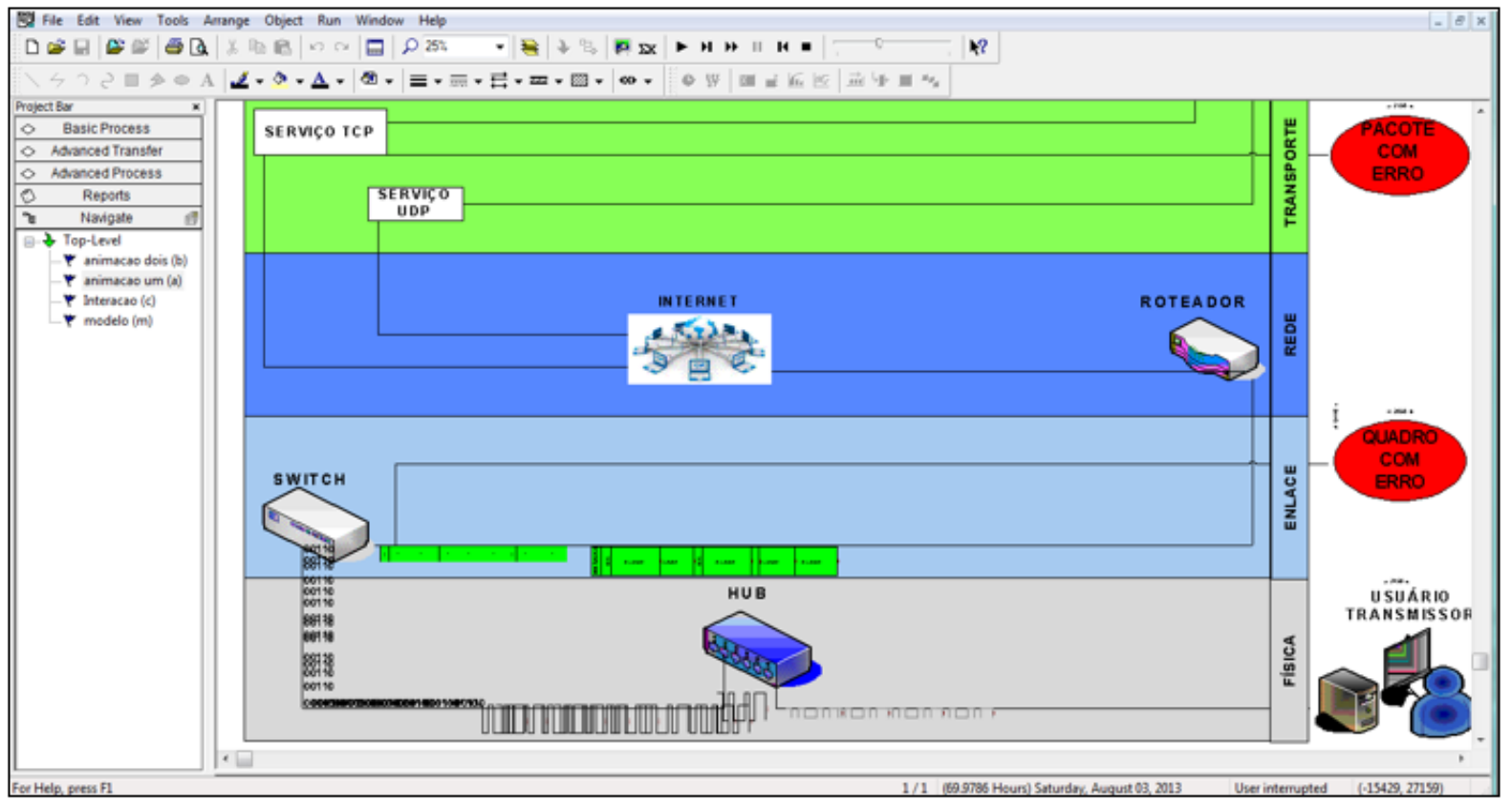

Figura 6 - Instante 1 da animação da parte "a" do modelo de simulação

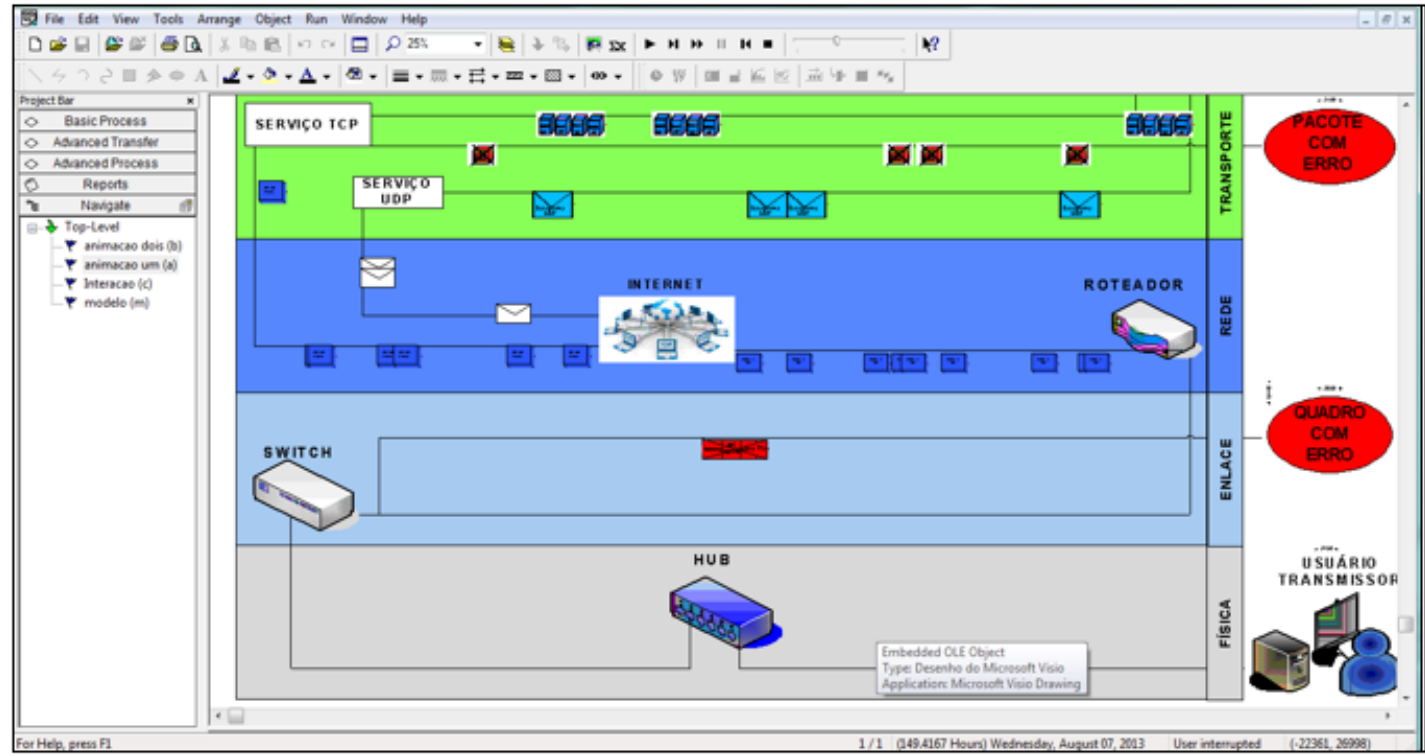

Figura 7 - Instante 2 da animação da parte "a" do modelo de simulação

A animação da camada física mostra a figura de um Hub representando um equipamento que trabalha neste nível. Além disto, é mostrado o sinal de entrada gerado pelo transmissor sendo amplificado e transformado em bit.

Na camada de enlace, o equipamento representado foi o switch, além de um ponto de descarte para quadros com erros. A animação desta camada mostra os quadros sendo gerados com endereço MAC de destino e origem, além de código de detecção de erro. Os quadros sem erro estão representados pela cor verde e os com erro estão representados pela cor vermelha.

$\mathrm{Na}$ camada de rede, estão representados o roteador e a Internet. Nesta camada, são mostrados os pacotes que foram formados com endereço IP em azul e os datagramas em branco.

A camada de transporte é representada juntamente com os protocolos TCP e UDP. O protocolo UDP irá transportar, através do serviço não confiável, os datagramas recebidos da camada de Rede. Já, o TCP será responsável pelo transporte confiável dos pacotes. Desta forma, pacotes identificados pela cor vermelha contêm erro e serão descartados. Os pacotes da cor azul são enviados para a próxima camada. 
Na parte "b" da animação, são representados os equipamentos e funções das camadas sessão, apresentação e aplicação, como mostram as Figura 8 e 9:

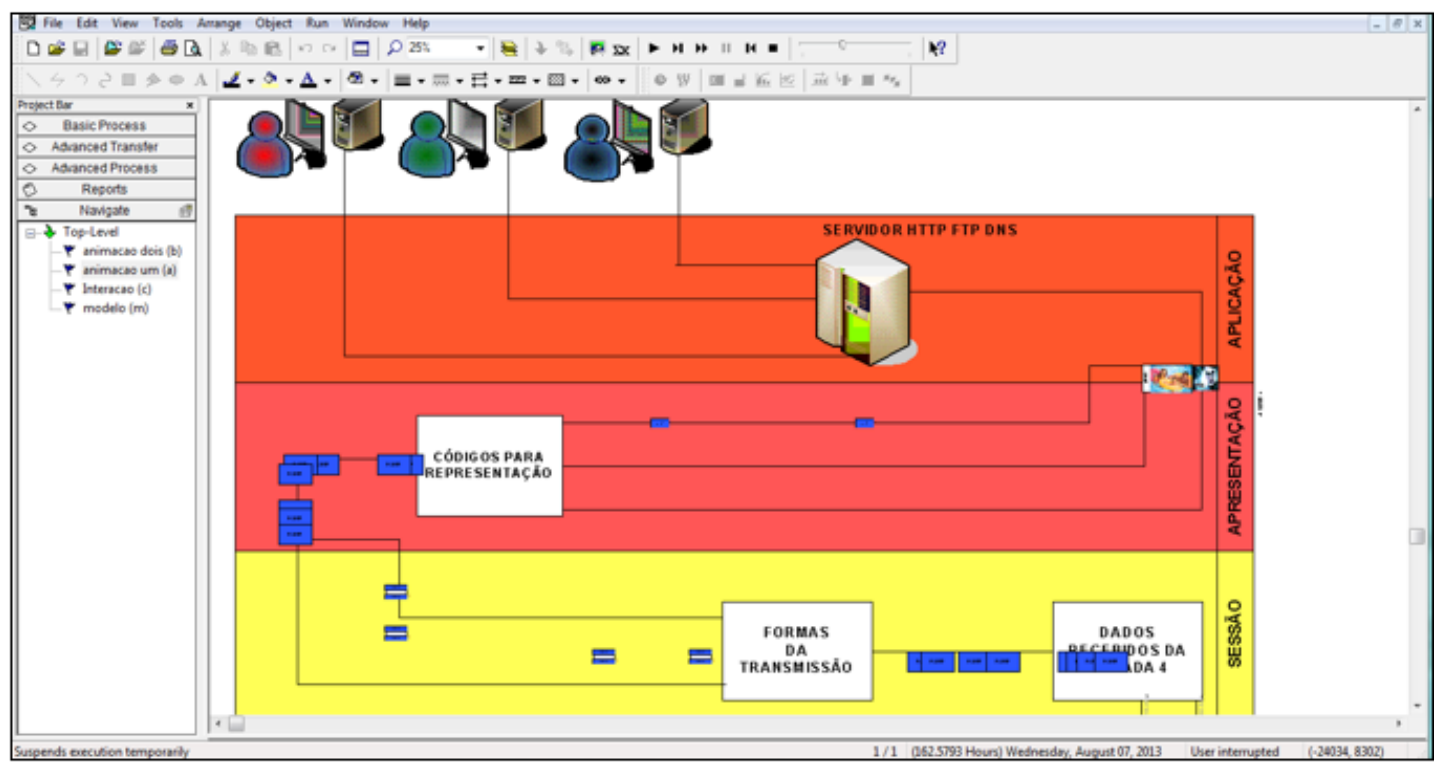

Figura 8 - Instante 1 da animação da parte "b" do modelo de simulação

Na representação da camada de sessão, é mostrada a recepção dos pacotes da camada de transporte, que são transmitidos pelo modo full ou half duplex.

A camada de apresentação mostra os dados sendo decodificados em imagens, vídeos e texto utilizando os códigos JPEG, MPEG e ASCII, respectivamente.

Já, a camada de aplicação mostra um servidor HTTP, FTP e DNS entregando os serviços aos três destinatários.

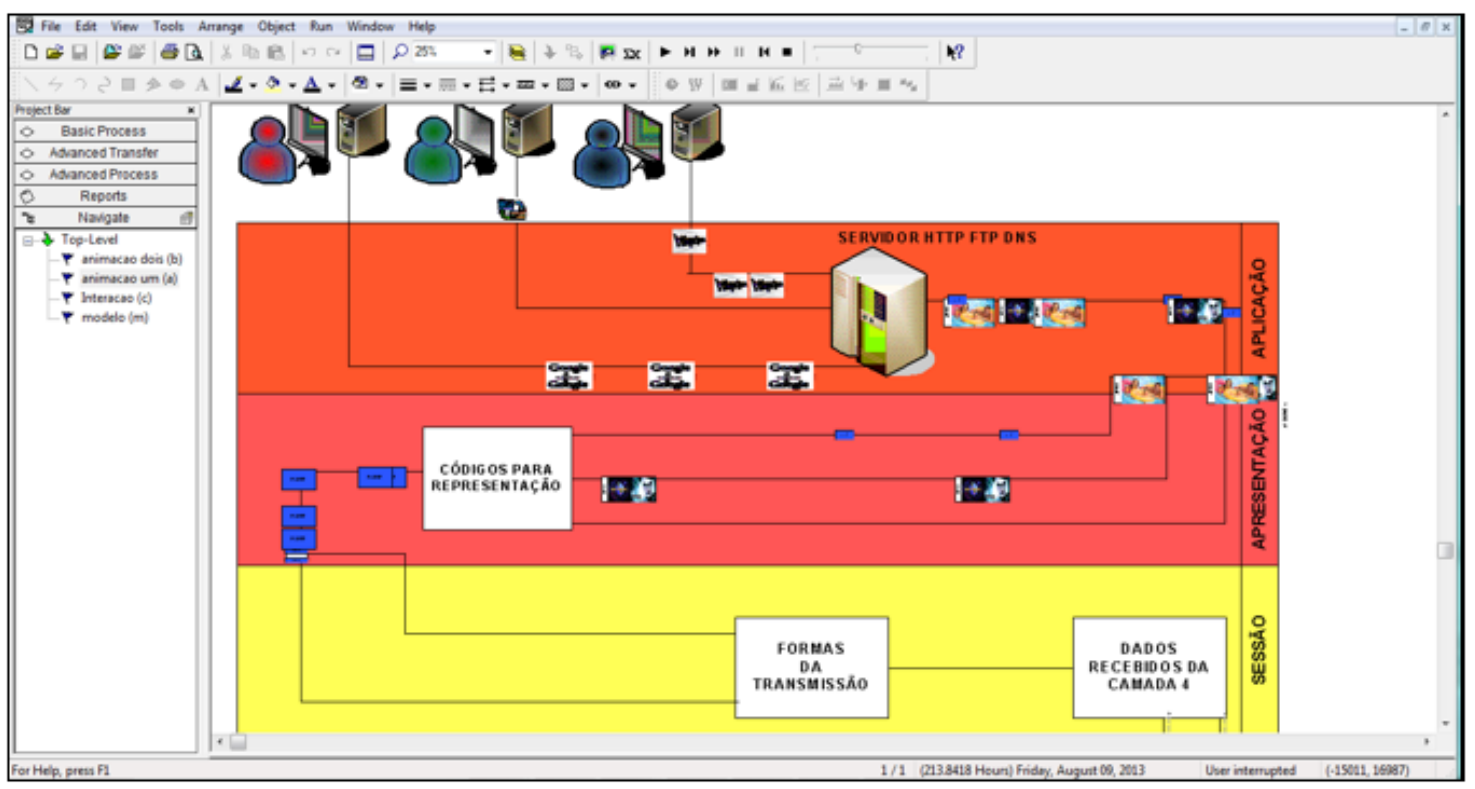

Figura 9 - Instante 2 da animação da parte "b" do modelo de simulação

\subsubsection{Testes com o modelo}

Com o término da construção do modelo e sua animação, iniciou-se a etapa de testes. Sua realização contou com a colaboração de três professores e cinco alunos que responderam um questionário sobre a capacidade do modelo em representar o que foi proposto e a qualidade da 
representação (animação). Esse questionário pode ser visto no Apêndice C. Além disto, também foi feita uma pesquisa de opinião sobre a mídia mais adequada para exibir o modelo em sala de aula.

$\mathrm{Na}$ avaliação do modelo pelo aluno, três dos cinco alunos concordaram totalmente com todos os oito itens do questionário. Com relação aos outros dois alunos, ambos concordaram parcialmente sobre um item que trata da capacidade de representação do conteúdo proposto e o segundo aluno não concordou nem discordou sobre dois itens relacionados à qualidade da animação do modelo.

Os resultados dos testes sobre a qualidade do modelo na visão dos alunos demonstraram que o modelo se encontrava pronto para ser implementado, porém, necessitando de ajustes na animação.

Com relação à mídia mais adequada para exibição do modelo, os alunos escolheram, respectivamente, o notebook de 14 polegadas, o computador de 17 polegadas, a TV de $42 \mathrm{e}$, por fim, o projetor de multimídia. Já, os três professores escolheram o computador, o notebook, a TV e o projetor multimídia, respectivamente.

É importante dizer que todas as mídias citadas anteriormente foram utilizadas na apresentação do modelo durante a etapa de testes. As respostas dos alunos mostram que os mesmos avaliaram as mídias sobre uma perspectiva individual, ou seja, cada um interagindo com o modelo.

De acordo com Smith e Strick (2001), a dificuldade de aprendizagem de um aluno pode ser constatada pelo baixo rendimento ou desempenho em atividades de leitura, escrita ou cálculo matemático. Neste contexto, um aumento do desempenho de um aluno em uma atividade avaliativa sobre um conteúdo ensinado sugere que houve aprendizagem. Sendo assim, para a avaliação do efeito do modelo na aprendizagem dos alunos, foram aplicados testes antes e depois da aula utilizando o modelo. A avaliação utilizada consta no Apêndice D. Os resultados dos testes podem ser visualizados na Tabela 1.

Tabela 1- Comparação dos resultados dos cinco alunos nas avaliações antes e após a aula

\begin{tabular}{cccc}
\hline Aluno & $\begin{array}{c}\text { Nota da Avaliação 1 } \\
(0-100 \%)\end{array}$ & $\begin{array}{c}\text { Nota da Avaliação 2 } \\
(0-100 \%)\end{array}$ & Variação percentual \\
\hline 1 & $33,3 \%$ & $77,8 \%$ & $134 \%$ \\
2 & $22,2 \%$ & $77,8 \%$ & $250 \%$ \\
3 & $33,3 \%$ & $88,9 \%$ & $167 \%$ \\
4 & $33,3 \%$ & $100,0 \%$ & $200 \%$ \\
5 & $55,6 \%$ & $100,0 \%$ & $80 \%$ \\
\hline Média & $35,54 \%$ & $88,90 \%$ & $150 \%$ \\
\hline
\end{tabular}

Na Tabela 1, é possível observar que a aula auxiliada pelo simulador didático contribuiu para uma melhora do desempenho dos cinco alunos nas avaliações aplicadas. Esse resultado pode sugerir que houve uma aprendizagem dos alunos, após terem contato com o simulador didático. Isto porque os alunos que já possuíam algum conhecimento adquirido em aulas teóricas anteriores, após terem aulas com o auxílio do simulador, tiveram uma variação percentual média de $150 \%$ em relação ao conhecimento adquirido anteriormente. A média destes alunos, após terem aulas com o simulador, aumentou de 35,54 para $88,90 \%$.

Vale ressaltar que essa avaliação mostrou que o modelo está pronto para ser aplicado em salas de aulas. Contudo, uma avaliação mais incisiva em relação à aprendizagem dos alunos só seria viável após a implementação do modelo em salas de aula com um grande número de alunos.

\subsubsection{Documentação e implementação}

A etapa de teste com o modelo confirmou que o mesmo já estava pronto para ser implementado. Contudo, antes de sua implementação, é necessário documentar todas as etapas realizadas em sua construção, de modo que outros professores possam usá-lo e modificá-lo, caso achem necessário. Este documento, que é composto pelo modelo conceitual e o passo a passo da construção do modelo computacional, está disponível na coordenação dos cursos onde o modelo foi implementado.

\subsection{Modelo para aula de física no ensino médio: reflexão e refração de luz}


O modelo procurou abordar alguns conceitos da óptica geométrica. Dentre eles, a Lei da Refração ou Lei de Snell, mostrada na equação (1). A referida lei expressa a diferença de caminho em termos do ângulo de projeção dos raios de luz e sua relação com os índices de refração de cada meio, $\mathrm{n} 1$ e $\mathrm{n} 2$, e $\theta 1$ e $\theta 2$, respectivamente.

$$
N_{1} \operatorname{sen} \theta_{1}=N_{2} \operatorname{sen} \theta_{2}
$$

O índice de refração de um meio é definido, conforme mostrado na equação (2), como uma relação entre a velocidade de propagação no vácuo e a velocidade de propagação naquele meio.

$$
N_{\text {meio }}=\frac{V_{\text {vácuo }}}{V_{\text {meio }}} \quad \text { onde } \quad \mathrm{V}_{\text {vácuo }}=3 \cdot 10^{8} \mathrm{~m} / \mathrm{s}
$$

\subsubsection{Formulação e análise do conteúdo}

A escolha da óptica geométrica se deu devido a sua característica abstrata, quando não relacionada a uma prática laboratorial. Como uma parte considerável das escolas públicas brasileiras não possui a infraestrutura necessária para a realização da prática de laboratório, o modelo desenvolvido em SED surge como uma alternativa, podendo ser utilizado em laboratórios de Informática que estão presentes em maior número nas instituições de ensino.

Quanto à caracterização contínua ou discreta, a luz é caracterizada como uma variável contínua, porém, foi possível discretizá-la para representar no ambiente de SED.

\subsubsection{Análise de viabilidade e definição dos objetivos}

As duas escolas onde o modelo foi testado possuíam laboratórios de Informática contendo computadores com monitores CRT (tubo de raios catódicos) de 14 polegadas. Essa infraestrutura foi suficiente para aplicar modelos interativos desenvolvidos em SED como ferramenta de auxilio didático.

Na definição dos objetivos, optou-se por representar os conceitos da reflexão e refração da luz, como: os ângulos de incidência, reflexão, refração e limite, além de índice de refração.

\subsubsection{Construção do modelo conceitual}

A Figura 10 e o Quadro 3 apresentam, respectivamente, o modelo conceitual e os parâmetros para serem utilizados na aula de Física. A entidade (L) gerada pelo modelo representa a onda de luz. O atributo neste modelo é o ângulo de incidência escolhido pelo aluno em uma interface através de uma planilha eletrônica. Além disso, na própria planilha, o ângulo limite também pode ser definido. A trajetória da luz é escolhida através de três funções "ou" (X1, X2 e X3), que direcionam a entidade de acordo com o ângulo de incidência, comparando-o com o ângulo limite. A onda de luz segue uma trajetória particular dependendo do atributo escolhido.

Em X1, se o ângulo incidente (atributo) escolhido for menor do que o ângulo limite, a entidade seguirá para R1. Caso o ângulo incidente seja igual ao ângulo limite, a entidade irá para R2. Agora, se o ângulo for maior do que o ângulo limite, a entidade seguirá pra R3. Posteriormente, todas as entidades, independente da trajetória percorrida, chegarão em R4 (Mudança de meio). De R4, as entidades novamente percorrerão trajetórias diferentes, dependendo do ângulo de incidência.

Em X2 e X3, se o ângulo incidente for menor do que o ângulo limite, a entidade será duplicada e seguirá para R5 (raio refletido) e para R8 (raio refratado). Se o ângulo for igual ao ângulo limite, a entidade será duplicada e seguirá para R6 (raio refletido) e para R9 (raio refratado). Porém, se o ângulo incidente for maior do que o ângulo limite, a entidade seguirá apenas para R7 (raio refletido). Neste caso, acontece a reflexão total da luz e, consequentemente, não existe raio refratado. 


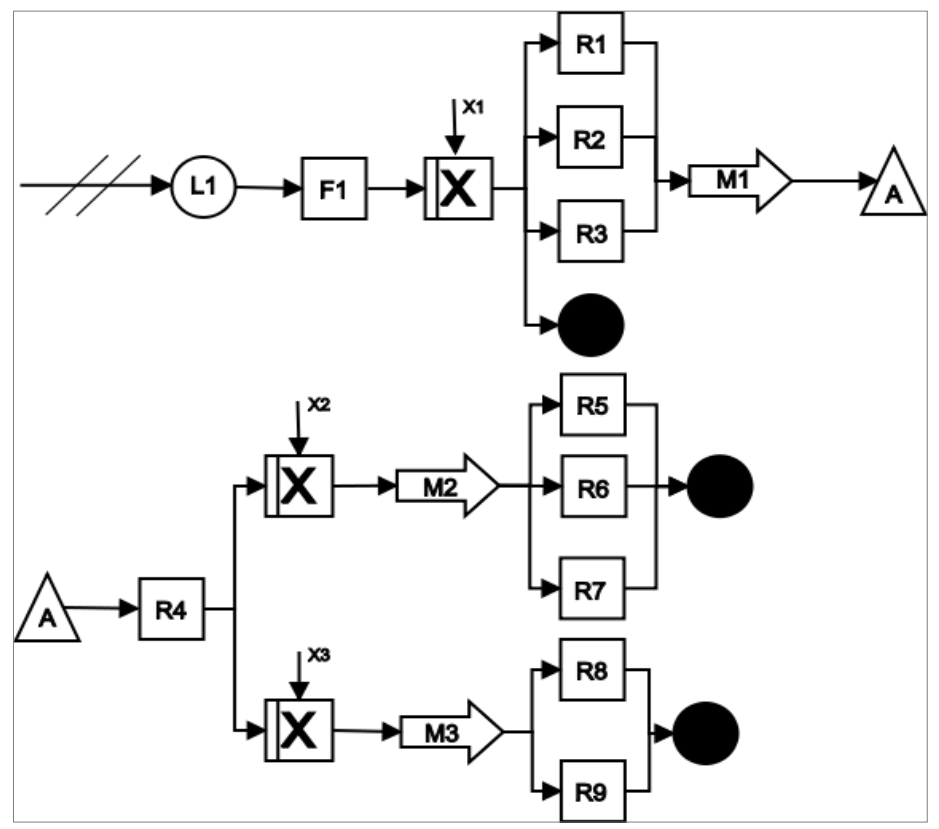

Figura 10 - Modelo conceitual

Quadro 3 - Parâmetros do modelo conceitual

\begin{tabular}{|c|c|c|}
\hline Item & Descrição & Parâmetros \\
\hline L1 & Entidade onda de luz & Constante, 1 hora; 2 por vez \\
\hline F1 & Fila onda de luz & Quantidade: 1 \\
\hline $\mathrm{X} 1$ & Função ou & $\begin{array}{l}\text { Se ângulo < L segue para R1 } \\
\text { Se ângulo }=L \text { segue para } R 2 \\
\text { Se ângulo }>L \text { segue para } R 3\end{array}$ \\
\hline R1 A R3 & Raios incidentes & Quantidade: 3 \\
\hline M1 & Movimentação para R4 & Quantidade: 1 \\
\hline R4 & $\begin{array}{l}\text { Meio - mudança na trajetória do raio / } \\
\text { mudança de meio (água/ar) }\end{array}$ & Quantidade: 1 \\
\hline $\mathrm{X} 2$ & Função ou & $\begin{array}{l}\text { Se ângulo }<L \text { L segue para R5 } \\
\text { Se ângulo }=L \text { segue para R6 } \\
\text { Se ângulo }>L \text { segue para } R 7\end{array}$ \\
\hline $\mathbf{X 3}$ & Função ou & $\begin{array}{l}\text { Se ângulo }<\text { L segue para R8 } \\
\text { Se ângulo }=\mathrm{L} \text { segue para } \mathrm{R9}\end{array}$ \\
\hline R5 A R7 & Raios Refletidos & Quantidade: 3 \\
\hline R8 E R9 & Raios Refratados & Quantidade: 2 \\
\hline S1 a S3 & Saídas & Quantidade: 3 \\
\hline
\end{tabular}

\subsubsection{Construção do modelo computacional}

O computador utilizado no desenvolvimento do modelo computacional foi um notebook com as mesmas características citadas anteriormente.

O simulador foi construído pelo próprio professor da disciplina, que utilizou o ambiente de simulação Arena em uma versão gratuita, disponibilizada para estudantes.

O modelo permite interação com o aluno através de uma planilha do Excel, que funciona como interface. Nela, o aluno pode inserir dados, como o ângulo de incidência do raio de luz, que serão visualizados na tela de animação do Arena.

O Quadro 4 descreve as características principais do modelo computacional apresentado neste estudo: 
Quadro 4 - Características do modelo de simulação

\begin{tabular}{|l|l|}
\hline Características & Software de simulação a eventos discretos \\
\hline Software de simulação & ARENA 14 \\
\hline Desenvolvedor & Professor da disciplina \\
\hline Tipo de licença & Gratuita \\
\hline Interatividade & Sim \\
\hline Permite alteração & Sim \\
\hline Modelo dinâmico & Sim \\
\hline Ajuste de visualização & Sim \\
\hline Tempo de desenvolvimento & 7 horas \\
\hline Carga horária de treinamento & 20 horas \\
\hline
\end{tabular}

O professor confeccionou o modelo em aproximadamente 7 horas, com um tempo de treinamento de 20 horas. O modelo permite ser alterado quantas vezes forem necessárias.

A Figura $11(a, b, c)$ apresenta três instantes da animação que representa a trajetória da luz ao propagar-se da água para o ar. Ela mostra os ângulos de reflexão e refração em função do ângulo de incidência escolhido.

A Figura 12 mostra a tela de entrada da planilha, onde os alunos puderam interagir com o modelo de simulação, inserir o valor para o ângulo de incidência do raio de luz.

\subsubsection{Testes com o modelo}

Os testes de verificação da qualidade do modelo em relação à capacidade de representação dos conceitos propostos e à animação foram feitos durante sua implementação. Isto porque, após sua confecção, o modelo de simulação já foi aplicado em 98 alunos do ensino médio nas aulas da disciplina de Física de duas escolas públicas estaduais do município de Campos dos Goytacazes (RJ/ Brasil).

Foi realizada uma análise da aprendizagem dos alunos com o modelo, onde ficou confirmada sua contribuição para o aumento do desempenho dos discentes conforme apresentado em Nascimento, (2012).

\subsubsection{Documentação e implementação}

A documentação deste modelo de simulação foi composta pelo modelo conceitual e o passo a passo da construção do modelo computacional.

Em relação à implementação, este modelo já se tornou uma ferramenta de ensino, sendo utilizada em alunos do curso técnico de nível médio em disciplinas de fibras ópticas de uma instituição federal de ensino na cidade de Campos dos Goytacazes-RJ. Além disto, este modelo foi disponibilizado para alunos e professores das escolas onde o modelo foi primeiramente implementado.

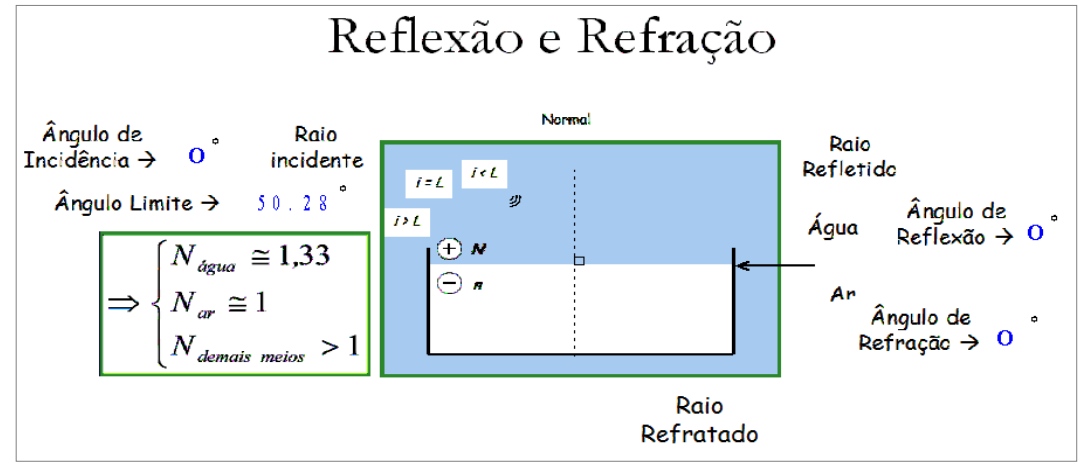

(a) 


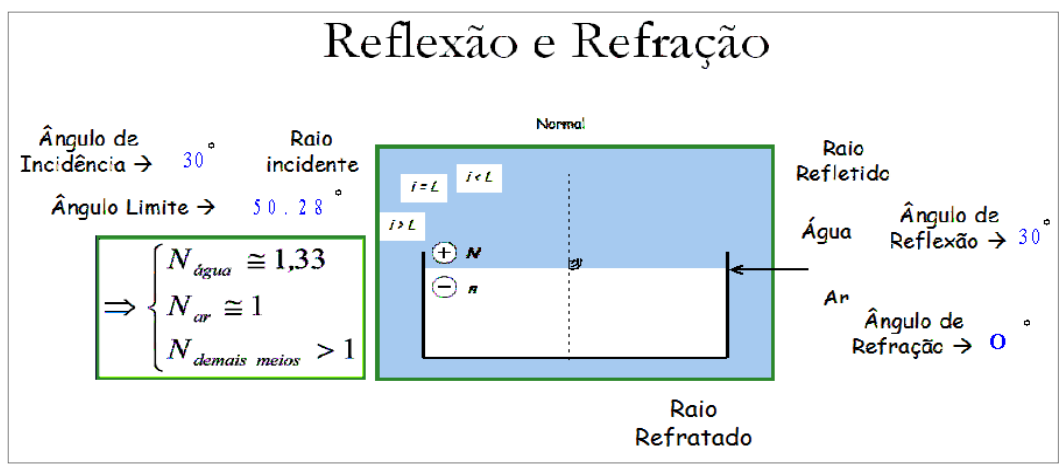

(b)

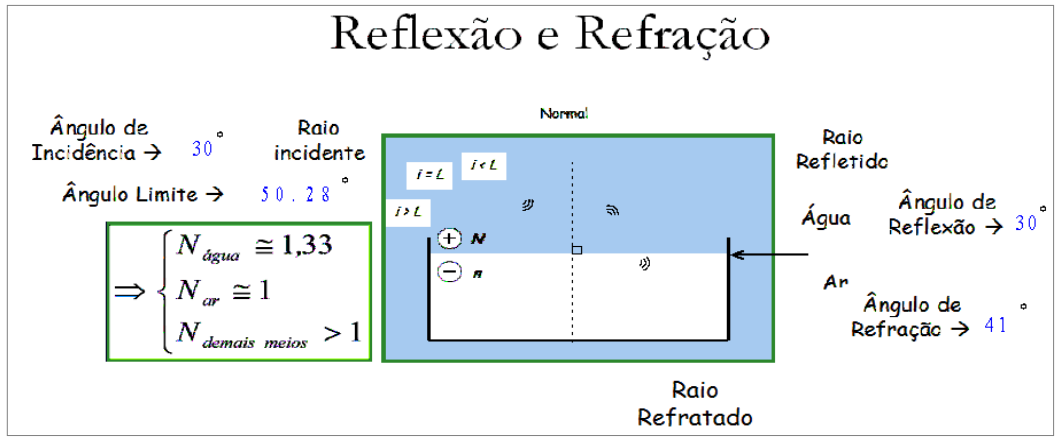

(c)

Figura 11 - Visualização de três instantes diferentes da execução do modelo de simulação. (a) instante inicial; (b) instante intermediário; e (c) Instante da fase final.

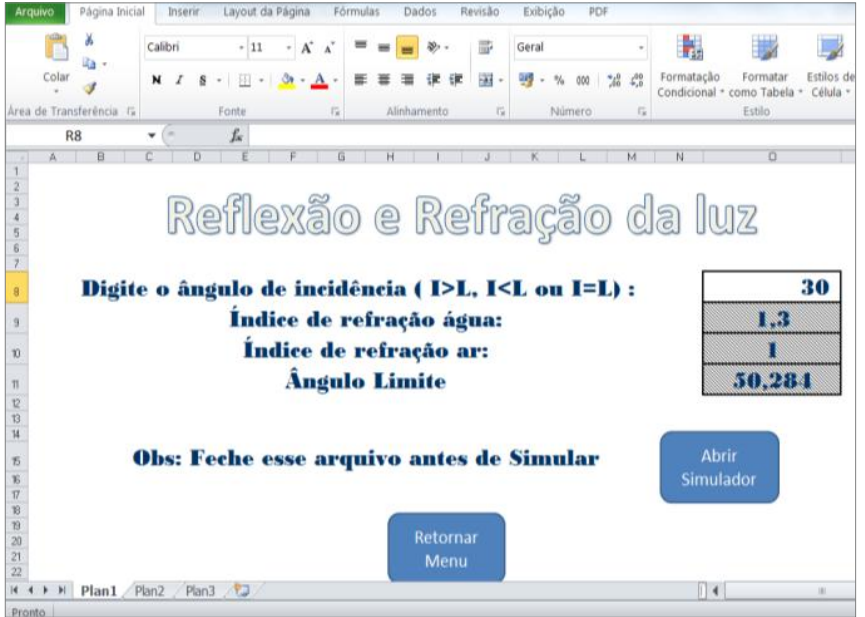

Figura 12 - Planilha eletrônica responsável por fazer a interface com o simulador

\section{Considerações finais}

Após a construção dos modelos de simulação para serem empregados como recursos didáticos em aulas das disciplinas de Informática e Física, em turmas de ensino médio, com a abordagem proposta, verificou-se que a mesma atendeu aos objetivos propostos. De certa forma, não se pode afirmar ainda que tais passos já podem ser amplamente empregados com este propósito. Este trabalho buscou iniciar e apresentar uma proposta de abordagem específica para a construção de modelos de simulação com o propósito didático de auxiliar a elaboração deste tipo de modelo de simulação. A abordagem se mostrou simples e eficiente para se atingir o objetivo almejado. Os primeiros testes realizados mostraram que pode ser um caminho a ser trilhado. 
Uma questão que se levanta neste trabalho é a necessidade de realização de maior número de testes para que a abordagem possa ser mais bem desenvolvida e consolidada. Tendo em vista que os passos aqui apresentados ainda estão em fase de desenvolvimento, é muito bem vinda à adesão de novas contribuições para a consolidação e aprimoramento da mesma. Pode ser sugerida também que seja avaliada a possibilidade de elaboração de uma espécie de tutorial para auxiliar professores nos primeiros passos com esta proposta. Outra questão que se abre é a possibilidade de investigação de novos campos, disciplinas ou tópicos onde poderia ser mais indicada a aplicação destes modelos, tanto no ensino médio como no superior.

É importante ainda ser destacado que, uma vez que um determinado professor receba um treinamento específico com este propósito, ele poderá elaborar inúmeros modelos, a partir daí. $\mathrm{Na}$ realidade, quanto mais um professor elabore os seus modelos com fins didáticos, mais ele estará apto a construir novos modelos e em tempo menor.

Em relação ao custo dos modelos de simulação empregados como recursos didáticos, destacase a possibilidade de utilização de versões livres de custos dos softwares de SED. Outra perspectiva que se abre é o fato de, atualmente, já existirem softwares de código aberto e livre de custos, que poderão ser amplamente utilizados para este fim. Inclusive, nesta direção, destaca-se o software Ururau apresentado em Peixoto et al. (2013).

\section{Agradecimentos}

Os autores gostariam de agradecer ao Conselho Nacional de Desenvolvimento Científico e Tecnológico - CNPq e à Fundação de Amparo à Pesquisa do Estado do Rio de Janeiro - FAPERJ pelo suporte financeiro para esta pesquisa.

\section{Referências}

BALCI, O.; DEATER-DECKARD, K.; NORTON, A. Challenges in Teaching Modeling and Simulation Online. In: Proceedings of the 2013 WINTER SIMULATION CONFERENCE. 2013, p. $3568-3575$.

BANKS, J.; CARSON, J. S.; NELSON, B. L.; NICOL, D. M. Discrete-Event System Simulation. Prentice Hall, $5^{\text {th }}$ ed, 2010.

FREITAS FILHO, P. J. Introdução à Modelagem e Simulação de Sistemas: com aplicações em Arena. 2. ed. Visual Books, 2008.

GOLDSMAN, D. A Simulation Course for High School Students. In Proceedings of the WINTER SIMULATION CONFERENCE, 2007.

LAW, A. M. Simulation modeling and analysis. 4th edition. McGraw-Hill, 2007.

MIRANDA, R. C.; MONTEVECHI, J. A. B.; PENTEADO, K. M.; AGUIAR, M. S.; PINHO, A. F. de. Análise de uma unidade de processamento de roupas de um hospital através da simulação a eventos discretos. Produto \& Produção, vol. 13, n. 3, p. 07-24, out. 2012.

MONTEVECHI, J. A. B.; LEAL, F.; PINHO, A. F.; COSTA, R. F. S.; OLIVEIRA, M. L. M.; SILVA, A. L. F. Conceptual modeling in simulation projects by mean adapted IDEF: An application in a Brazilian tech company. In: Proceedings of the WINTER SIMULATION CONFERENCE, 2010, p. 1624-1635.

MONTEVECHI, J. A. B.; LEAL, F.; MIRANDA, R. C.; PEREIRA, T. F. Interactive Learning of Modeling and Discrete-Events Simulation Through Lego ${ }^{\circledR}$ Parts. In: Proceedings of the 2013 WINTER SIMULATION CONFERENCE. 2013, p. 3556-3567. 
NASCIMENTO, J. R.; RANGEL, J. J. A. Modelos de Simulação a Eventos Discretos como Recursos Didáticos no Ensino Médio. In SIMPÓSIO BRASILEIRO DE PESQUISA OPERACIONAl, Rio de Janeiro. XVI CLAIO - XLIV SBPO, 2012, p. 1-10.

PEIXOTO, T. A.; RANGEL, J. J. A.; MATIAS, I. O.; MONTEVECHI, J. A. B.; MIRANDA, R. C. Ururau - Um Ambiente para Desenvolvimento de Modelos de Simulação a Eventos Discretos. Revista Pesquisa Operacional para o Desenvolvimento, 2013, v. 5, p. 373-405.

RANGEL, C. L.; RANGEL, J. J. A. (2013). Simulação a Eventos Discretos como Ferramenta Pedagógica nas Áreas de Telecomunicações e Informática. In: IX ENCONTRO MINEIRO DE ENGENHARIA DE PRODUÇÃO - EMEPRO, 2013.

RANGEL, J. J. A.; TEIXEIRA, A. C. T.; SHIMODA, E.; LISBÔA, R. T. Simulação a eventos discretos como recurso didático em disciplina de física no Ensino. S \& G. Sistemas \& Gestão, 2010, v.6, 56-71.

SARGENT, R. G. Verifications and validation of simulations models. Journal of Simulation, 2013, vol. 7 , no. 1 , p. 12-24.

SILVA, T. M. P.; RANGEL, J. J. A.; SHIMODA, E.; NASCIMENTO, J. R. Discrete Event Simulation to Building Simulators for Teaching. Journal of Simulation, v. 8, p. 325-334, 2014.

SMITH, C.; STRICK, L. (2001). Dificuldades de Aprendizagem de A a Z: um guia completo para pais e educadores. Porto Alegre; Artes Médicas.

STÅHL, I.; BORN, R. \& HERPER, H. Teaching Simulation to Ten Thousand students AmericanEuropean Cooperation and Perspectives. In: Proceedings of the 2013 WINTER SIMULATION CONFERENCE. 2013, p. 3576-3587.

WHITE JR, K. P; INGALLS, R. G. Introduction to Simulation. WINTER SIMULATION CONFERENCE, Austin, TX, USA p. 12-23, 2009. 
Apêndices

Apêndice A - modelo Conceitual de cada Camada do Modelo OSI 

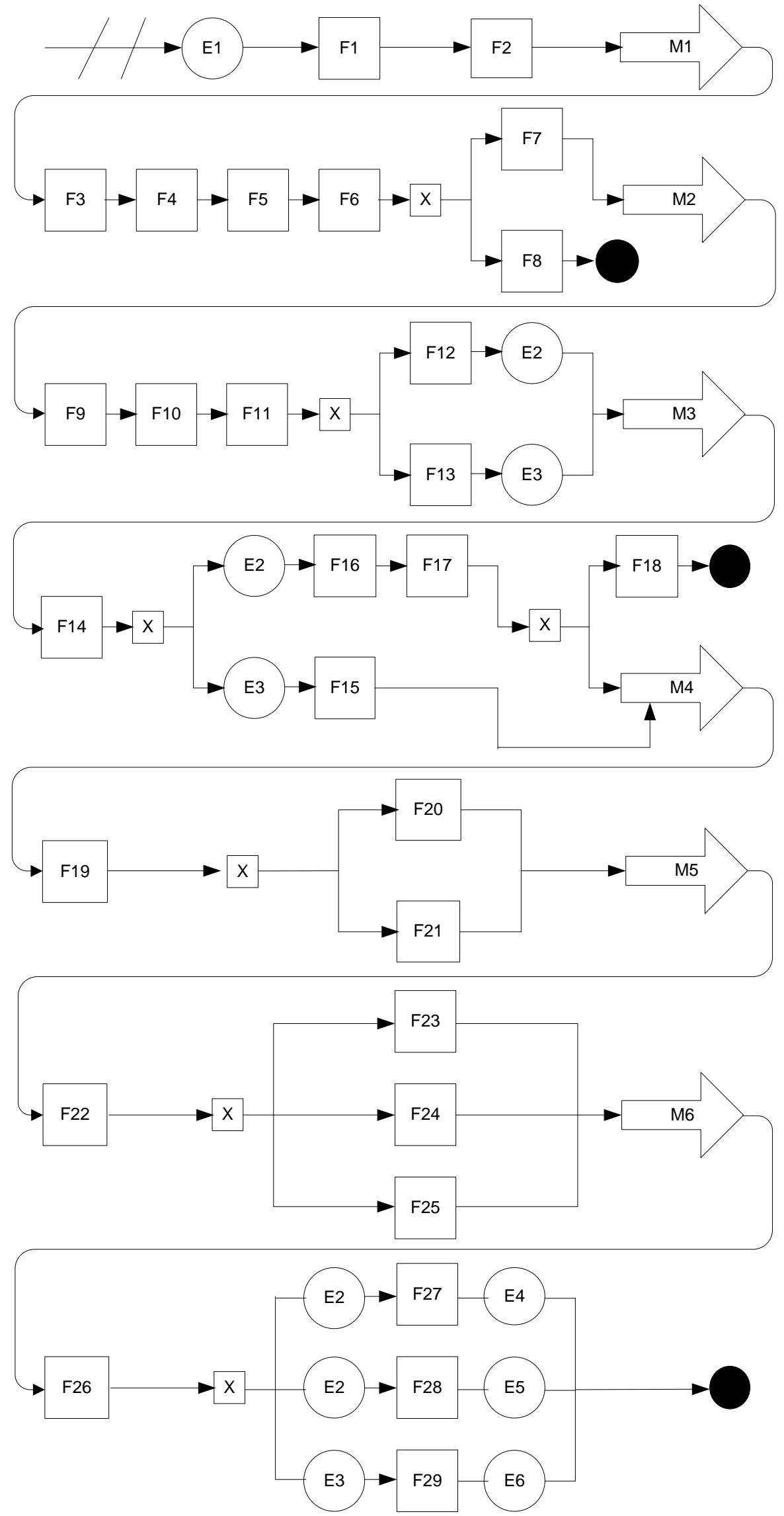


\begin{tabular}{|c|c|c|c|c|c|}
\hline Item & Descrição & Parâmetros & Item & Descrição & Parâmetros \\
\hline E1 & $\begin{array}{l}\text { Informação de } \\
\text { entrada }\end{array}$ & $\begin{array}{l}\text { Constante; } 1 \text { por vez; } \\
\text { Max. } 100\end{array}$ & F16 & $\begin{array}{l}\text { Controla fluxo } \\
\text { dos pacotes TCP }\end{array}$ & $\begin{array}{l}\text { Triangular; } 1 \text { por vez; } \\
\text { min. } 0,5 ; \text { max. } 1.5\end{array}$ \\
\hline E2 & Pacote TCP & Constante; 1 por vez; & F17 & $\begin{array}{l}\text { Controla erros e } \\
\text { sequência nos } \\
\text { pacotes TCP }\end{array}$ & $\begin{array}{l}\text { Triangular; } 1 \text { por vez; } \\
\text { min. } 0,5 ; \max .1 .5\end{array}$ \\
\hline E3 & Datagrama UDP & Constante; 1 por vez & F18 & $\begin{array}{l}\text { Descarta pacotes } \\
\text { com erro }\end{array}$ & $\begin{array}{l}\text { Triangular; } 1 \text { por vez; } \\
\text { min. } 0,5 ; \text { max. } 1.5\end{array}$ \\
\hline E4 & $\begin{array}{l}\text { Dados do servidor } \\
\text { FTP }\end{array}$ & Constante; 1 por vez & F19 & $\begin{array}{l}\text { Gerencia e } \\
\text { controla sessão }\end{array}$ & 2 -way by chance; $80 \%$ \\
\hline E5 & $\begin{array}{l}\text { Dados do servidor } \\
\text { HTTP }\end{array}$ & Constante; 1 por vez & F20 & Sessão Half & $\begin{array}{l}\text { Triangular; } 1 \text { por vez; } \\
\text { min. } 0,5 ; \text { max. } 1.5\end{array}$ \\
\hline E6 & $\begin{array}{l}\text { Dados do servidor } \\
\text { DNS }\end{array}$ & Constante; 1 por vez & F21 & Sessão Full & $\begin{array}{l}\text { Triangular; } 1 \text { por vez; } \\
\text { min. } 0,5 ; \max .1 .5\end{array}$ \\
\hline $\mathrm{F} 1$ & Amplificação & $\begin{array}{l}\text { Triangular; } 1 \text { por vez; } \\
\text { min. } 0,5 ; \text { max. } 1.5\end{array}$ & F22 & $\begin{array}{l}\text { Representa dados } \\
\text { baseado no } \\
\text { formato }\end{array}$ & $\begin{array}{l}\text { N-way by chance; } 40 \%, 30 \% \text {, } \\
30 \%\end{array}$ \\
\hline $\mathrm{F} 2$ & $\begin{array}{l}\text { Define bit "1" e bit } \\
\text { "0" }\end{array}$ & $\begin{array}{l}\text { Triangular; } 1 \text { por vez; } \\
\text { min. } 0,5 ; \max .1 .5\end{array}$ & F23 & $\begin{array}{l}\text { Representa texto } \\
\text { através do ASCII }\end{array}$ & $\begin{array}{l}\text { Triangular; } 1 \text { por vez; } \\
\text { min. } 0,5 ; \max .1 .5\end{array}$ \\
\hline $\mathrm{F} 3$ & Forma quadros & & F24 & $\begin{array}{l}\text { Representa vídeo } \\
\text { através do MPEG }\end{array}$ & $\begin{array}{l}\text { Triangular; } 1 \text { por vez; } \\
\text { min. } 0,5 ; \text { max. } 1.5\end{array}$ \\
\hline $\mathrm{F} 4$ & Define MAC & $\begin{array}{l}\text { Triangular; } 1 \text { por vez; } \\
\text { min. } 0,5 ; \max .1 .5\end{array}$ & F25 & $\begin{array}{l}\text { Representa foto } \\
\text { através do JPEG }\end{array}$ & $\begin{array}{l}\text { Triangular; } 1 \text { por vez; } \\
\text { min. } 0,5 ; \text { max. } 1.5\end{array}$ \\
\hline F5 & $\begin{array}{l}\text { Insere controle de } \\
\text { erro }\end{array}$ & $\begin{array}{l}\text { Triangular; } 1 \text { por vez; } \\
\text { min. } 0,5 ; \max .1 .5\end{array}$ & F26 & $\begin{array}{l}\text { Identifica o } \\
\text { serviço }\end{array}$ & $\begin{array}{l}\mathrm{N} \text {-way by chance; } 50 \%, 25 \% \text {, } \\
25 \%\end{array}$ \\
\hline F6 & Inspeciona quadros & $\begin{array}{l}\text { Triangular; } 1 \text { por vez; } \\
\text { min. } 0,5 ; \max .1 .5\end{array}$ & F27 & Serviço do HTTP & $\begin{array}{l}\text { Triangular; } 1 \text { por vez; } \\
\text { min. } 0,5 ; \text { max. } 1.5\end{array}$ \\
\hline F7 & $\begin{array}{l}\text { Fila de acesso ao } \\
\text { meio }\end{array}$ & Delay 2 segundos & F28 & Serviço do FTP & $\begin{array}{l}\text { Triangular; } 1 \text { por vez; } \\
\text { min. } 0,5 \text {; max. } 1.5\end{array}$ \\
\hline F8 & $\begin{array}{l}\text { Descarta quadro } \\
\text { com erro }\end{array}$ & $\begin{array}{l}\text { Triangular; } 1 \text { por vez; } \\
\text { min. } 0,5 ; \text { max. } 1.5\end{array}$ & F29 & Serviço do DNS & $\begin{array}{l}\text { Triangular; } 1 \text { por vez; } \\
\text { min. } 0,5 ; \max .1 .5\end{array}$ \\
\hline F9 & Forma pacotes & $\begin{array}{l}\text { Triangular; } 1 \text { por vez; } \\
\text { min. } 0,5 ; \text { max. } 1.5\end{array}$ & M1 & $\begin{array}{l}\text { Envia os bits para } \\
\text { camada } 2\end{array}$ & Route time 30 segundos \\
\hline F10 & Define IP & $\begin{array}{l}\text { Triangular; } 1 \text { por vez; } \\
\text { min. } 0,5 ; \text { max. } 1.5\end{array}$ & M2 & $\begin{array}{l}\text { Envia os quadros } \\
\text { para camada } 3\end{array}$ & Route time 2 segundos \\
\hline F11 & $\begin{array}{l}\text { Faz roteamento } \\
\text { baseado no serviço }\end{array}$ & 2-way by chance; $75 \%$ & M3 & $\begin{array}{l}\text { Envia os pacotes } \\
\text { para camada } 4\end{array}$ & Route time 10 segundos \\
\hline $\mathrm{F} 12$ & $\begin{array}{l}\text { Serviço orientado a } \\
\text { conexão }\end{array}$ & $\begin{array}{l}\text { Triangular; } 1 \text { por vez; } \\
\text { min. } 0,5 \text {; max. } 1.5\end{array}$ & M4 & $\begin{array}{l}\text { Envia os dados } \\
\text { para camada } 5\end{array}$ & Route time 10 segundos \\
\hline F13 & $\begin{array}{l}\text { Serviço não } \\
\text { orientado a } \\
\text { conexão }\end{array}$ & $\begin{array}{l}\text { Triangular; } 1 \text { por vez; } \\
\text { min. } 0,5 ; \text { max. } 1.5\end{array}$ & M5 & $\begin{array}{l}\text { Envia os dados } \\
\text { para camada } 6\end{array}$ & Route time 10 segundos \\
\hline F14 & $\begin{array}{l}\text { Define o protocolo } \\
\text { conforme F12/ F13 }\end{array}$ & $\begin{array}{l}\text { Triangular; } 1 \text { por vez; } \\
\text { min. } 0,5 ; \text { max. } 1.5\end{array}$ & M6 & $\begin{array}{l}\text { Envia os dados } \\
\text { para camada } 7\end{array}$ & Route time 10 segundos \\
\hline F15 & $\begin{array}{l}\text { Entrega os } \\
\text { datagramas UDP }\end{array}$ & $\begin{array}{l}\text { Triangular; } 1 \text { por vez; } \\
\text { min. } 0,5 ; \text { max. } 1.5\end{array}$ & M6 & $\begin{array}{l}\text { Envia os dados } \\
\text { para camada } 7\end{array}$ & Route time 10 segundos \\
\hline
\end{tabular}




\section{Apêndice C - Questionário para Avaliação da Qualidade do Modelo na Percepção do Aluno e Professor}

O objetivo principal deste modelo de simulação é representar conceitos abordados no estudo sobre as camadas do Modelo de Referência OSI.

Os objetivos específicos do modelo são:

A Representar as principais funções realizadas em cada camada.

A Mostrar como ocorre o processo de encapsulamento e desencapsulamento da informação, conforme a mesma percorre as camadas do modelo.

A Mostrar a atuação de alguns protocolos em cada camada do modelo.

1) No que se refere ao objetivo proposto no modelo, julgue as afirmações a seguir:

a) O modelo de simulação representa os conceitos propostos no objetivo.
(1) discordo
(2) discordo
(3) nem concordo
(4) concordo
completamente
parcialmente
nem discordo
parcialmente
(5) concordo completamente
(N) não sei

b) $\mathrm{O}$ modelo permite visualizar as funções realizadas em cada camada.
(1) discordo completamente
(2) discordo parcialmente
(3) nem concordo
(4) concordo parcialmente
(5) concordo completamente
(N) não sei

c) O modelo permite visualizar o processo de encapsulamento e desencapsulamento das informações no modelo.
(1) discordo
(2) discordo completamente parcialmente
(3) nem concordo nem discordo
(4) concordo parcialmente
(5) concordo completamente
(N) não sei

d) O modelo permite visualizar a atuação dos protocolos representados em cada camada.
(1) discordo (2) discordo
parcialmente (3) nem concordo
nem discordo (4) concordo
parcialmente
(5) concordo completamente
(N) não sei completamente

2) Sobre a qualidade das imagens apresentadas, julgue as afirmativas a seguir:

a) As imagens do modelo são claras
(1) discordo
(2) discordo completamente parcialmente
(3) nem concordo nem discordo
(4) concordo parcialmente
(5) concordo completamente

(N) não sei

b) É possível perceber detalhes da imagem durante a animação
(1) discordo
(2) discordo
(3) nem concordo parcialmente nem discordo
(4) concordo parcialmente
(5) concordo completamente
(N) não sei completamente

3) No que se refere a interação do modelo, julgue as afirmativas a seguir:

a) Você conseguiu interagir com o modelo.
(2) discordo parcialmente
(3) nem concordo nem discordo
(4) concordo parcialmente
(5) concordo completamente
(N) não sei completamente air informação a partir da interação.

b) Você conseguiu extrair informação a partir da interação.
(1) discordo completamente parcialmente
nem discordo
(4) concordo parcialmente
(5) concordo completamente
(N) não sei

4) No que se refere a qualidade da imagem durante a exibição do modelo, enumere os itens a seguir ordenando as mídias, da mais adequada ( $1^{\circ}$ Lugar $)$ a inadequada ( $4^{\circ}$ Lugar):
( )Computador com tela de 17 polegadas

$$
\begin{aligned}
& 1 \text { - } 2^{\circ} \text { Lugar } \\
& 2-2^{\circ} \text { Lugar } \\
& 3-3^{\circ} \text { Lugar } \\
& 4-4^{\circ} \text { Lugar }
\end{aligned}
$$$$
3 \text { - } 3^{\circ} \text { Lugar }
$$$$
\text { ( ) TV com tela de LED de } 42 \text { polegadas }
$$

5) Dê a sua opinião sobre o modelo de simulação didático apresentado: 


\section{Apêndice D - Teste para Avaliação da Aprendizagem do Aluno}

\section{AVALIAÇÃO DA APRENDIZAGEM DO ALUNO TESTE SOBRE O CONTEÚDO SIMULADO NO MODELO}

Nome:

1) Com relação ao número de camadas do modelo OSI, marque a opção correta:
a) Possui 6 camadas
d) Possui 3 camadas.
b) Possui 8 camadas
e) Nenhuma das alternativas
anteriores.

c) Possui 7 camadas.

2) Relacione o nome de cada camada abaixo de acordo com o número de sua posição dentro do Modelo OSI:

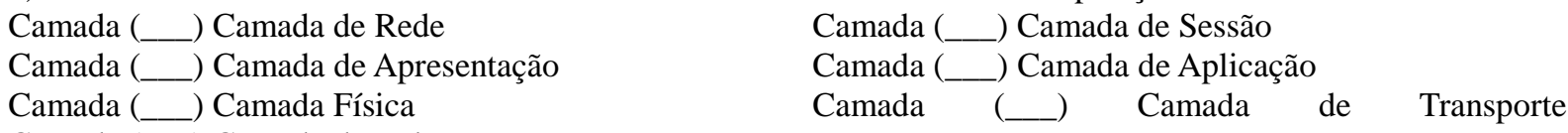

Camada (__ Camada de Enlace

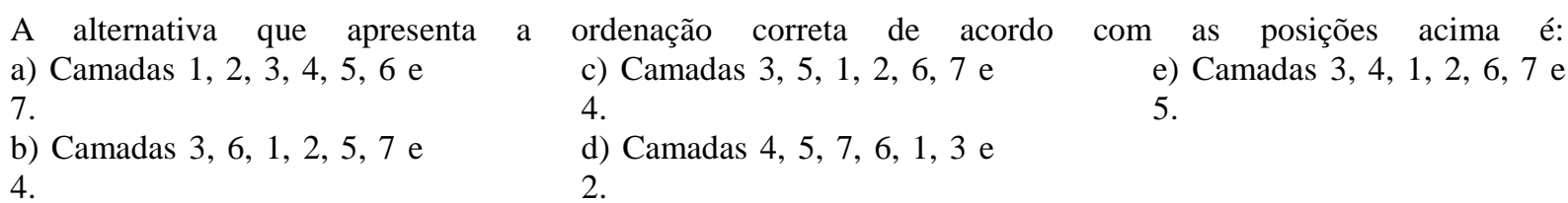

3) Faz parte das funções do modelo OSI exceto:

a) Ao passar pelas camadas, adicionar um cabeçalho aos dados do usuário a serem transmitidos para outro sistema, modificando sua estrutura.

b) Permitir que sistemas de protocolos e fabricantes diferentes se comuniquem.

c) Trata a informação a medida que passa pelas camadas, prestando serviço para camada imediatamente superior.

d) Garantir que somente redes com protocolos iguais se comuniquem.

e) Nenhuma das alternativas

4) Sobre o processo de encapsulamento e desencapsulamento, julgue (V) para verdadeiro e (F) para falso:

( ) É o processo onde as informações vão adquirindo novos formatos, a medida que passam pelas camadas do modelo OSI.

( ) No encapsulamento os dados vão perdendo algumas informações de cabeçalho a medida que passa pelas camadas.

( ) No desencapsulamento, os dados vão adquirindo novas informações no campo de cabeçalho a medida que passa pelas camadas do modelo OSI.

( ) As informações vão ficando mais robustas conforme alcançam as camadas superiores.

( ) Na primeira camada os dados estão no formato mais simples.

A alternativa que apresenta o correto julgamento dos itens acima é: $\begin{array}{lll}\text { a) F, V, F, F e V. } & \text { c) V, F, F, V e V. } & \text { e) V, F, F, V e F. }\end{array}$
b) V, V, F, V e F.
d) V, F, F, F e V.

5) Sobre o formato da PDU em cada camada do modelo OSI, associe a segunda coluna de acordo com a primeira:
(1) Bits ou sinal
(2) Quadros ou frames
(3) Pacote ou datagramas
(4) Seguimentos
(5) Dados

( ) Camada Transporte

( ) Camadas Sessão, apresentação e aplicação.

( ) Camada Física

( ) Camada Enlace

( ) Camada Rede
A alternativa que
a) $4,2,1,3$ e 5 .
representa a associação
c) $4,5,1,3$ e 2 .
b) $3,5,1,2$ e 4 .
d) $4,5,1,2$ e 3 .
6) Informe os nomes das camadas que realizam as seguintes funções abaixo:
( ) Realiza a leitura dos bits, identificando a informação, endereço MAC de origem, endereço MAC de destino e inserindo método de detecção de erro.
) Representa os dados através de códigos apropriados para que o dispositivo de destino possa 
compreender a informação, como foto e texto.

( ) Trata a informação a nível de sinal, amplificando o mesmo e diferenciando "0" e "1".

aplicativos.

) Presta serviço diretamente para o usuário, entregando a informação através de seus

(

) Faz o roteamento dos pacotes e datagramas a partir do endereço IP, sem acompanhar os

pacotes pela rede.

(

Full Duplex.

) Controla o diálogo entre dois hosts, podendo alterar a forma de comunicação para Half ou

) Transporta os dados, garantindo que os pacotes cheguem ao destino.

A alternativa que representa a sequência dos nomes das camadas de acordo com a descrição das funções acima é:

a) Enlace, apresentação, física, aplicação, transporte, sessão e rede.

b) Transporte, sessão, rede, física, aplicação, enlace e apresentação.

c) Enlace, apresentação, física, aplicação, rede, sessão e transporte.

d) Física, apresentação, enlace, aplicação, sessão e transporte.

e) Nenhuma das alternativas anteriores.

7) Informe a camada onde os protocolos, codificações

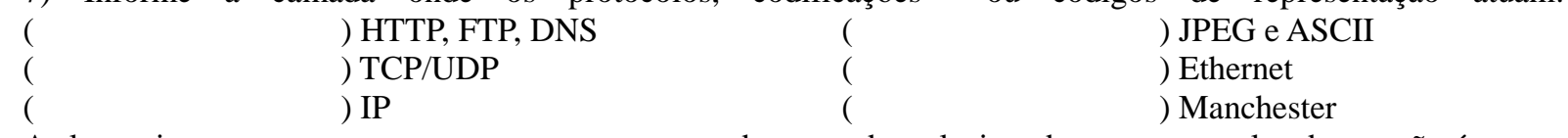

A alternativa que representa corretamente os nomes das camadas relacionados aos protocolos de atuação é:

a) Apresentação, transporte, rede, aplicação, enlace e física.

b) Aplicação, transporte, rede, apresentação, enlace e física.

c) Transporte, sessão, rede, física, aplicação, enlace e apresentação.

d) Aplicação, transporte, rede, apresentação, física e enlace.

e) Nenhuma das alternativas anteriores.

8) Se existe a ocorrência de um aumento dos dados transmitidos em uma rede, esta pode gerar atraso conforme seu estado atual. Neste contexto, qual o termo adequado para o controle de bits enviado ao mesmo tempo na rede?
a) Controle de sequência.
c) Controle de fluxo
e) NDA
b) Controle de erro.
d) Controle de bits.

9) Marque a alternativa que apresenta um dispositivo de rede usado na camada de enlace, rede e física, respectivamente:
a) HUB, roteador e bridge.
c) Bridge, roteador e conector.
e) NDA
b) Roteador, cabo e switch.
d) Switch, hub e roteador. 